\title{
Assessment of the Feasibility of Developing a Hanford Site Weld Modeling Program
}
D. G. Atteridge
W. E. Anderson
R. F. Klein

November 1986

\section{Prepared for}

UNC Nuclear Industries, Inc. and Rockwell Hanford Operations

under Contract DE-AC06-76RLO 1830

Pacific Northwest Laboratory

Operated for the U.S. Department of Energy

by Battelle Memorial Institute 


\title{
DISCLAIMER
}

This report was prepared as an account of work sponsored by an agency of the United States Government. Neither the United States Government nor any agency thereof, nor Battelle Memorial Institute, nor any of their employees, makes any warranty, expressed or implied, or assumes any legal liability or responsibility for the accuracy, completeness, or usefulness of any information, apparatus, product, or process disclosed, or represents that its use would not infringe privately owned rights. Reference herein to any specific commercial product, process, or service by trade name, trademark, manufacturer, or othenwise, does not necessarily constitute or imply its endorsement, recommendation, or favoring by the United States Government of any agency thereof, or Battelle Memorial Institute. The views and opinions of authors expressed herein do not necessarly state or reflect those of the United States Government or any agency thereof, or Battelle Memorial Institute.

\author{
PACIFIC NORTHWEST LABORATORY \\ operated by \\ BATTELLE \\ for the \\ UNITED STATES DEPARTMENT OF ENERGY \\ under Contract DE-AC06-76RLO 1830
}

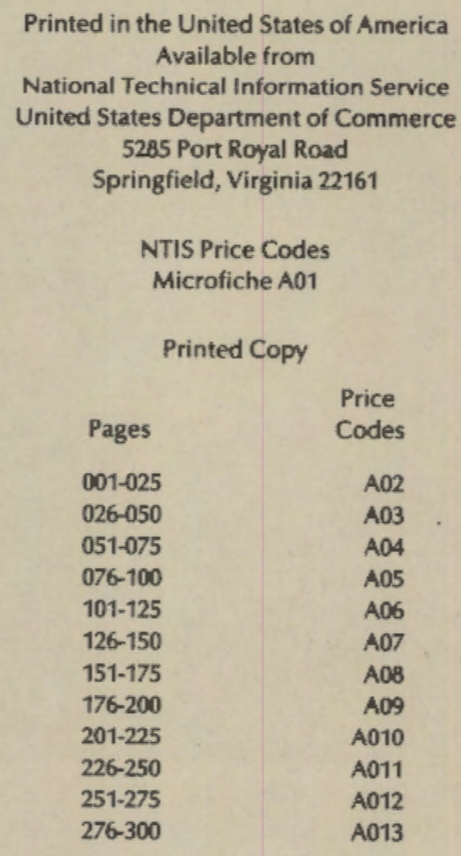


ASSESSMENT OF THE FEASIBILITY OF DEVELOPING A HANFORD SITE WELO MODELING PROGRAM

D. G. Atteridge

W. E. Anderson

R. F. Klein

November 1986

Prepared for

UNC Nuclear Industries, Inc. and Rockwell Hanford Operations

under Contract DE-AC06-76RLO 1830

Pacific Northwest Laboratory

Richland, Washington 99352 


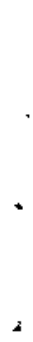

2 


\section{ABSTRACT}

Welding on the Hanford Site is an everyday occurrence, and most of the weldments made on site are relatively straightforward. Groove geometries, weld filler materials, and choice of welding techniques and welding parameters are normally decided by past experience or weld handbook advice. However, there are other weldments that might employ new materials, as well as one-of-a-kind welding situations not covered by previous experience or by work reported in the literature.

Implementation of a verified analytical weld assessment method would allow: 1) optimization of weld metal and heat-affected zone microstructure, and 2) optimization of variables that affect structural deformation and residual stresses. These improvements would maximize structural stability and minimize service-induced environmental degradation. Development of this modeling capability can be expected to decrease weld parameter development costs and greatly reduce the lead time (or system down-time) needed to develop these parameters for unique welding or repair-welding conditions.

Realistic prediction of weldment thermal and strain history will require the use of a finite element model. Microstructure and resultant properties can be predicted using complex computer-based microstructure evolution models, literature-based empirical equations, or experimentally established behaviors.

This report, prepared for UNC Nuclear Industries, Inc. and Rockwell Hanford Operations by Pacific Northwest Laboratory, examines the feasibility of developing analytical methods for establishing weld parameter envelopes in new, complex welded configurations. 


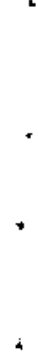




\section{CONTENTS}

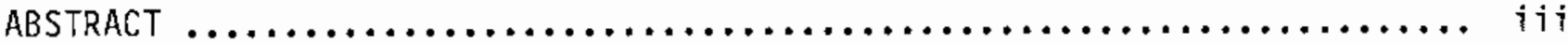

ASSESSMENT OF THE FEASIBILITY OF DEVELOPING A HANFORD SITE

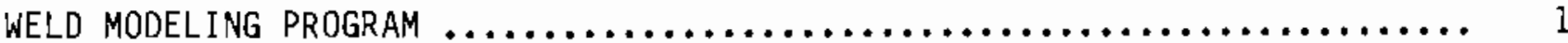

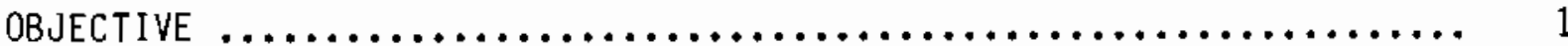

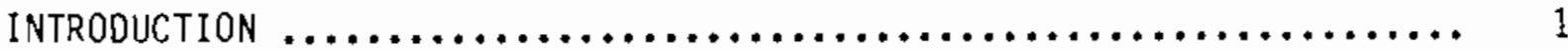

TASK 1: ASSESSMENT OF THERMOMECHANICAL WELD MODELING FEASIBILITY . ...... 3

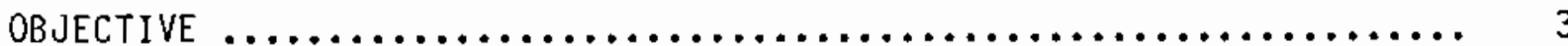

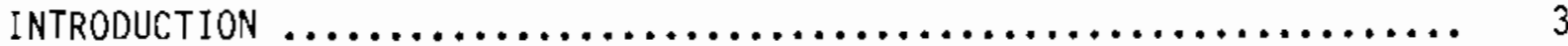

FINITE ELEMENT MODELING $\ldots \ldots \ldots \ldots \ldots \ldots \ldots \ldots \ldots \ldots \ldots \ldots \ldots \ldots \ldots \ldots$

PRACTICAL APPROACHES TO DEVELOPING A WELD MODELING

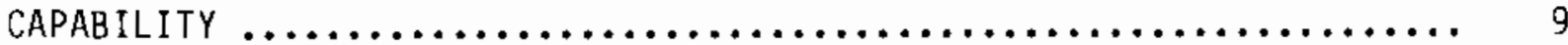

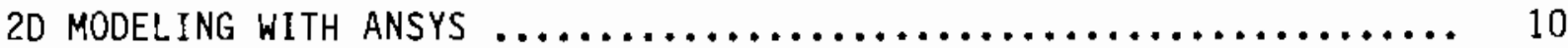

THE 20 AND 3D CAPABILITIES OF THE GOLDAK MODEL $\ldots \ldots \ldots \ldots \ldots \ldots \ldots \ldots \ldots$

USER-FRIENDLY FRONT ENDS $\ldots \ldots \ldots \ldots \ldots \ldots \ldots \ldots \ldots \ldots \ldots \ldots \ldots \ldots \ldots \ldots \ldots$

TASK 2: ASSESSMENT OF WELD METAL AND HEAT-AFFECTED-ZONE MICROSTRUCTURAL

EVOLUTION PREDICTION TECHNIQUES $\ldots \ldots \ldots \ldots \ldots \ldots \ldots \ldots \ldots \ldots \ldots \ldots \ldots$

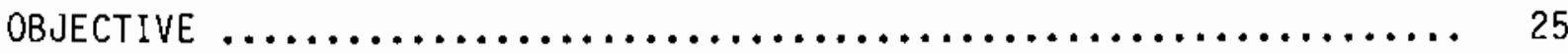

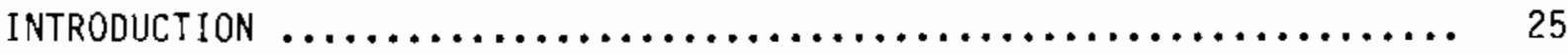

MICROSTRUCTURAL EVOLUTION PREDICTION ILLUSTRATIONS $\ldots \ldots \ldots \ldots \ldots \ldots \ldots$

TASK 3: PREDICTION TECHNIQUES FOR MICROSTRUCTURE-RELATED MATERIAL

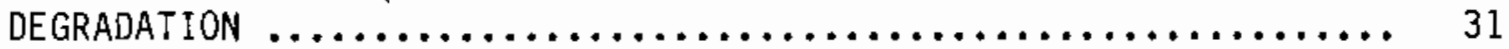

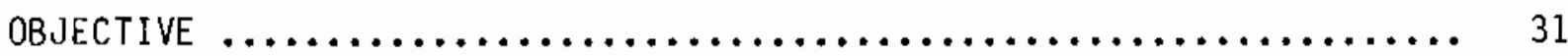

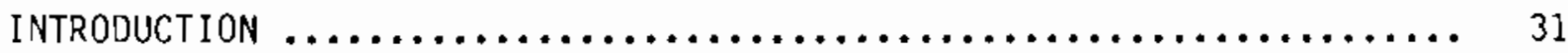

EXAMPLE MECHANICAL PROPERTY PREDICTIONS $\ldots \ldots \ldots \ldots \ldots \ldots \ldots \ldots \ldots \ldots \ldots \ldots$ 
CONCLUSIONS AND RECOMMENDATIONS $\ldots \ldots \ldots \ldots \ldots \ldots \ldots \ldots \ldots \ldots \ldots \ldots \ldots, 41$

NEAR-TERM MODELING GOALS $\ldots \ldots \ldots \ldots \ldots \ldots \ldots \ldots \ldots \ldots \ldots \ldots \ldots \ldots, 41$

LONG-TERM MODELING GOALS $\ldots \ldots \ldots \ldots \ldots \ldots \ldots \ldots \ldots \ldots \ldots \ldots \ldots, 42$

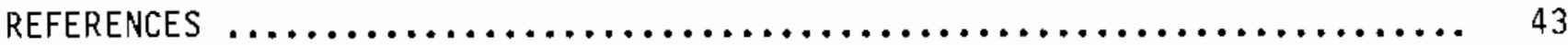




\section{FIGURES}

1 Goldak Model of Double-Ellipsoid Weld Pool heat Source ........... 4

2 Comparison of Actual Weldment with 20 Weld Simulation Model ....... 7

3 Schematic Illustrating Comparable TM History Measurement

Planes in Real Plate Weld and 20 Simulation .................. 8

4 FEM-Predicted Thermal Profiles for the Inside Surface of

4- and 14-in.-dia. Schedule 80 Type 304 SS Pipe Girth

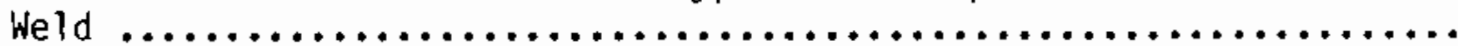

5 Measured and FEM-Predicted Thermal Profiles for the Inside Surface of a 24-in.-dia. Schedule 80 Type 3D4 SS Pipe Girth Weld .......... 12

6 FEM-Predicted Maximum Extent of Isotherms for the First Three Passes in a 1-in.-Wall, 24-in.-dia. Schedule 80 SS Pipe

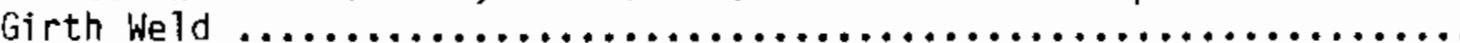

7 FEM-Predicted Maximum Extent of Isotherms for the First Three Passes in a 1-in.-Wa11, 24-in.-dia. Schedule 80 CS Pipe

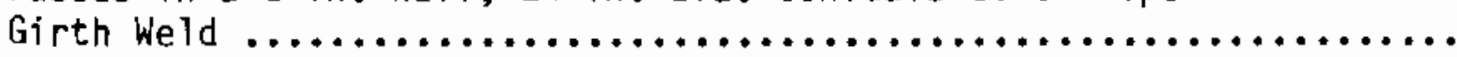

8 Comparison of the Effect of heat Input on the Size of the Fusion Zone Between CS and SS 24-in.-dia. Pipe Girth Welds

9 Thermal Conductivity and Specific Heat as a Function of Temperature for $\mathrm{CS}$ and $\mathrm{SS}$

10 Comparison of the Effect of Air with that of Water Present in the Inside of the SS Pipe During Welding on Fusion Zone Size and Isotherm Configurations

11 Comparison of the Effect of Air with that of Water Present in the Inside of the CS Pipe During Welding on Fusion Zone Size and Isotherm Configurations.

12 FEM-Predicted Weld Metal Heating and Cooling Characteristics ........

13 Comparison of a Uniform FEM Computation Mesh and McDill's Graded Mesh for Modeling a Cube

14 Comparison of Measured and Predicted Isothermally Induced Sensitization Development in Stainless Steel $\ldots \ldots \ldots \ldots \ldots \ldots \ldots \ldots \ldots$

15 Predicted Instantaneous Sensitization Development in the HAZ on the Inside Surface of a 14-in.-dia. Schedu?e 160 SS Pipe Girth weld. 
16 Predicted Post-Pass Sensitization Development for the HAZ on the Inside Surface of a 14-in.-dia. Schedule 160 SS Pipe Girth Weld ..... 29

17 HAZ Sensitization Development: 24-in.-dia. TM Weid ............ 30

18 Prediction of Sensitization Development Regions in SS Pipe Girth Weld from FEM-Predicted Isotherms .................... 32

19 Relation of CS Weld Reheat Zones to Equilibrium Phases

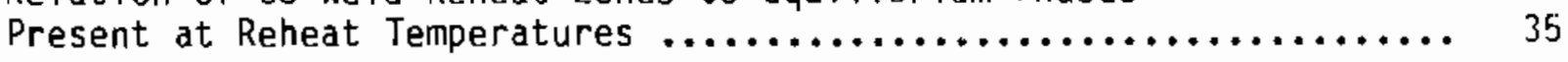

20 Prediction of Coarse-Grained Regions in CS Pipe Girth Weld from FEM-Predicted Isotherms .......................... 36

21 Prediction of Coarse-Grained Regions in CS Pipe Girth Weld Fabricated Using Butter-Bead Technique from FEM-Predicted Isotherms

22 Approximate Correlation of Hardness, Time to Failure, and Appiied Stress for CS for $3000 \mathrm{ppm}$ Hydrogen Sulfide in a $5 \% \mathrm{NaCl}$ Solution ... 


\section{ASSESSMENT OF THE FEASIBILITY OF DEVELOPING A}

HANFORD SITE WELD MDDELING PROGRAM

\section{OBJECTIVE}

The objective of this program is to determine the feasibility of developing analytical methods for establishing weld parameter envelopes in new, complex welded configurations.

INTRODUCTION

Welding on the Hanford Site is an everyday occurrence, and most of the weldments made on site are relatively straightforward. Groove geometries, weld filler materials, and choice of welding techniques and welding parameters are normally decided by past experience or weld handbook advice. However, there are other weldments that might employ new materials, as well as one-of-a-kind welding situations not covered by previous experience or by work reported in the literature.

Implementation of a verified analytical weld assessment method would allow: 1) optimization of weld metal and heat-affected zone (HAZ) microstructure, and 2) optimization of variables that affect structural deformation and residual stresses. These improvements would maximize structural stability and minimize service-induced environmental degradation. Development of this modeling capability can be expected to decrease weld parameter development costs and greatiy reduce the lead time (or system down-time) needed to develop these parameters for unique welding or repair-welding conditions.

Potential applications include: primary welds, repair welds, air- and water-backed welds, and auxiliary pipes welded to water-filled pipes. Potential fabrication materials include: stainless steels, ferritic steels, superalloys, titanium alloys and aluminum alloys.

The weld assessment method is expected to include the following steps:

1) calculation of thermal and strain characteristics of a weld/repair as a function of weld parameters, joint characteristics, and base material (Task 1) 
2) estimation of weld metal and HAZ microstructural evolution resulting from weld-induced thermomechanical (TM) history (Task 2)

3) prediction of resultant properties such as hardness, toughness, corrosion potential, and stress-corrosion cracking (SCC) resistance of the weld metal and HAZ microstructures (Task 3 ).

Realistic prediction of weldment thermal and strain history will require the use of a finite element model (FEM). Microstructure and resultant properties can be predicted using complex computer-based microstructure evolution models, literature-based empirical equations, or experimentally established reaction behaviors.

This report discusses the results of a Pacific Northwest Laboratory $(P N L)(a)$ investigation of the feasibility of developing a Hanford Site weld modeling program. The report was prepared for UNC Nuclear Industries, Inc. and Rockwell Hanford Operations, who are jointly conducting the U.S. Department of Energy-sponsored weld modeling program.

(a) Operated for the U.S. Department of Energy by Battelle Memorial Institute. 


\section{TASK 1: ASSESSMENT OF THERMOMECHANICAL WELD MODELING FEASIBILITY}

\section{OBJECTIVE}

The objective of this task is to assess the applicability of finite element modeling to the calculation of thermomechanical weld histories as the first step in developing a method for establishing Hanford Site-specific weld parameter envelopes.

\section{INTRODUCTION}

Four major regions need to be defined quantitatively in order to model the TM aspects of welding: 1) the welding heat source, usually an arc of some type; 2) the molten metal pool; 3) the HAZ; and 4) the structure (or structural component) containing the weldment. Both measurement and modeling results are needed to quantify interactions taking place among all four regions.

Considerable measurement work is being done to gain a better understanding of welding arc physics; one example is the work by Key's $(1,2,3,4)$ group at the Idaho National Engineering Laboratory (INEL), which is directed at defining: 1) efficiency of heat energy transferred from the source to the part being welded, 2) energy density distribution functions of heat energy impinging on the weldment surface, and 3 ) effect of arc forces on shape and stirring characteristics of the molten weld pool.

Models that predict arc properties from first principles are not presently available even for stationary arcs impinging on flat plates, let alone for a moving arc confined in a groove. There is still controversy over arc efficiency heat transfer numbers and arc heat transfer modeling. Thus a simplified arc efficiency term combined with an assumed heat distribution function, based on experimentation, is a realistic approach to the present state of the art in arc heat transfer modeling.

There also are arc forces that shape the top surface of the weld pool; these generally create standing waves in the pool and form a depression zone beneath the arc, perturbing temperature distributions in the pool and affecting 
solidification dynamics as well as pool shape contours. Modeling of these effects is beginning, but they are assessed empirically, or ignored, at the present time.

Modeling of the molten metal pool is also receiving considerable attention, particularly the effects of impurities on pool stirring characteristics. Heiple $e^{(5,6)}$ at Rocky Flats demonstrated that surface tension of the molten pool determines stirring characteristics and that trace impurities control surface tension changes. Models of stationary arc situations have been developed, but description. of molten pool geometries for traveling arcs in grooves is beyond the present state of the art.

Goldak at Carleton University $(7)$ has developed a reasonable, empirically based approach to the modeling of weld pools; the shape is approximated from actual measurements, using double (or quadruple) ellipsoids. Heat input distribution over the weld pool is assumed to be Gaussian. Heat transfer due to arc-induced stirring of the liquid pool is taken into account by using an abnormally high conductivity value for molten material. An example of this weld pool modeling is shown in Figure 1.

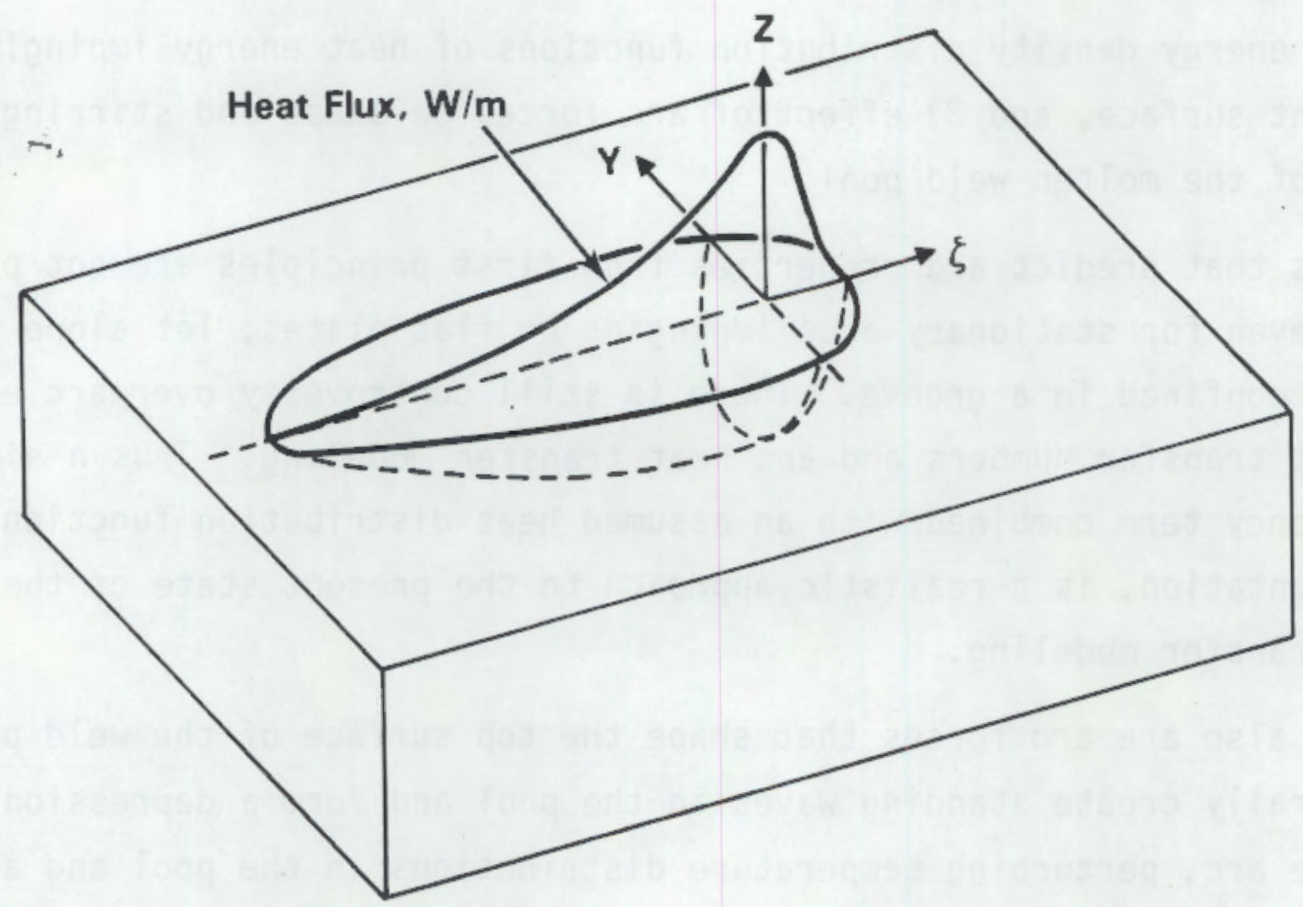

FIGURE 1. Goldak Model of Double-Ellipsoid Weld Pool Heat Source 
The above discussion covers thermal properties of the molten pool; the other areas of concern are: 1) weld pool solidification microstructure evolution and 2) fusion zone shrinkage characteristics. Quasistatic weld pool solidification characteristics can be estimated from models that are now being developed. Stresses and strains resulting from molten pool solidification and fusion zone contraction are being modeled by Mahin at Sandia Livermore ${ }^{(8,9)}$ and Goldak $(7,10,11,12)$ and provide useful guidance. Wider-ranging information is still needed, however.

The HAZ and the structure or structural component containing the weldment are, theoretically, the easiest regions to model thermally, as they are ruled by solid-state heat transfer. Mahin $(8,9)$ and Goldak $(7,10,11,12)$ are modeling the thermal stress/strain relationships resulting from weld-induced heating and cooling.

While the state of the art in weld modeling research is such that all four regions are being treated (the work being directed by Mahin is an example of theoretical approaches to complete weld modeling), the practical state of the art is that only thermal histories associated with the HAZ and the structural component containing the weldment can be realistically modeled, particularly in multipass welding/repairing situations. The work of Goldak is an instance of sophisticated, pragmatic weld modeling.

Thus, the long-term objective of a Hanford Site weld modeling program should be to develop modeling capabilities that input weld parameters and output microstructure, deformation, and strain characteristics for all weld regions using models based on first principles. The near-term goal is to provide useful weld parameter evaluations, and the state of the art indicates that the effect of welding parameters on HAZ properties is a realistic near-term goal. This is fortuitous since HAZ properties are generally controlling in real-world engineering structures; the base metal compositions can be selected to provide satisfactory wrought or cast properties, and weld metal alloys can be selected to provide satisfactory as-cast properties. In general, weldrelated, fracture-critical regions develop in the HAZ, where base material microstructure has been compromised by heat and deformation related to the welding operation. Research and field practice have shown that welding 
parameters can be adjusted to prevent or minimize development of undesirable microstructures and residual stress states. Modeling provides the opportunity to establish desirable process ranges without commitment to extended trial-anderror test programs.

It is therefore recommended that the near-term thrust of Hanford Site weld modeling efforts be directed at the HAZ; the long-term thrust, at the total weldment.

\section{FINITE ELEMENT MODELING}

Finite element modeling can be used to represent engineering components and structures. It can also be used to simulate both thermal heat from, and the stress/strain responses of, structural materials to specific thermal and mechanical loads. Both thermal and mechanical loads result from the welding process.

Finite element modeling of welds can be conducted in two (2D) or three dimensions (3D). The 20 case can realistically represent thermal history conditions under steady-state welding and specific boundary restraints. It is relatively easy to set up and inexpensive to use. The 3D case is more complex and expensive, but must be used for realistic modeling of nonsteady-state conditions and weld-induced stresses and deformations.

In $2 D$ axisymmetric cases, the weld can be treated as if heating is imposed instantaneously along the complete weldment; model examples are illustrated in Figure 2. The first is a bead-on-pipe girth weld, simulated as if the total length of the final weldment is heated and cooled at the same rate. The second example is a bead-on-plate weld. It is simulated as if the complete length of the infinitely long weldment were instantaneously heated. In real-world conditions, a molten pool of finite dimensions travels along the plate surface; this process is simulated by heating up the complete weld line at one time.

The $2 D$ model calculates TM responses to thermal input for a plane of material perpendicular to the weld axis in the middle of the infinitely long plate. Heat intensity can be varied as a function of time to simulate the heating and 
Actual Weld

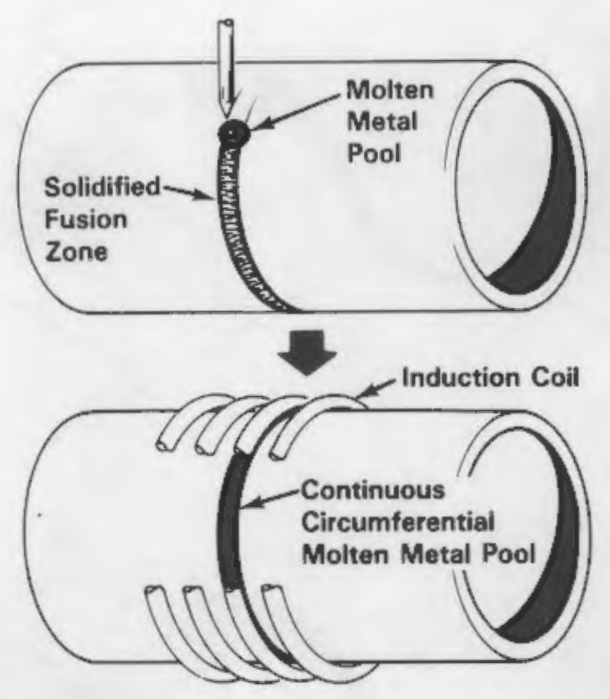

Weld Simulation

\section{Actual Weld}

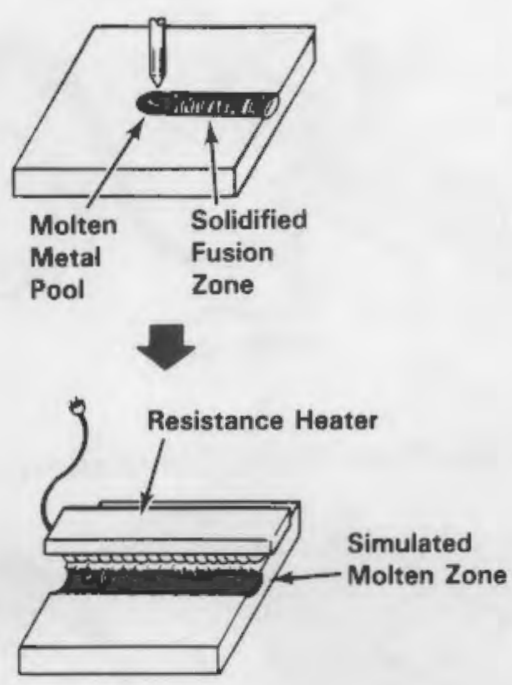

2-D Weld Simulation

FIGURE 2. Comparison of Actual Weldment with 2D Weld Simulation Model

cooling experienced by that plane of material in the real weld as the molten pool passes by. Thus the complete weld-induced thermal cycle can be modeled, as illustrated in Figure 3.

A 2D weld model works well for calculating thermal history if the archeated volume of material in the weld to be simulated is small in comparison to the volume of welded material; hence it is a reasonable approach for cases in which weld pool heating affects only a small portion of weldment length, such as in the middle of a thick-walled, large-diameter pipe weld.

The $2 D$ modeling cannot be expected to simulate correctly those weld situations where preheating or postheating effects dominate, as in welding thin, small-diameter pipe. It can, however, take into account an externally imposed uniform pre- or post-weld heat treatment.

Selected stresses and deformations resulting from welding, such as those induced perpendicular to the weld axis, can be estimated by 20 modeling. These results will not be entirely correct as their magnitude and sign generally depend on material constraint along the weld axis as well as beside it. 


\section{Bead-On-Plate Weld}

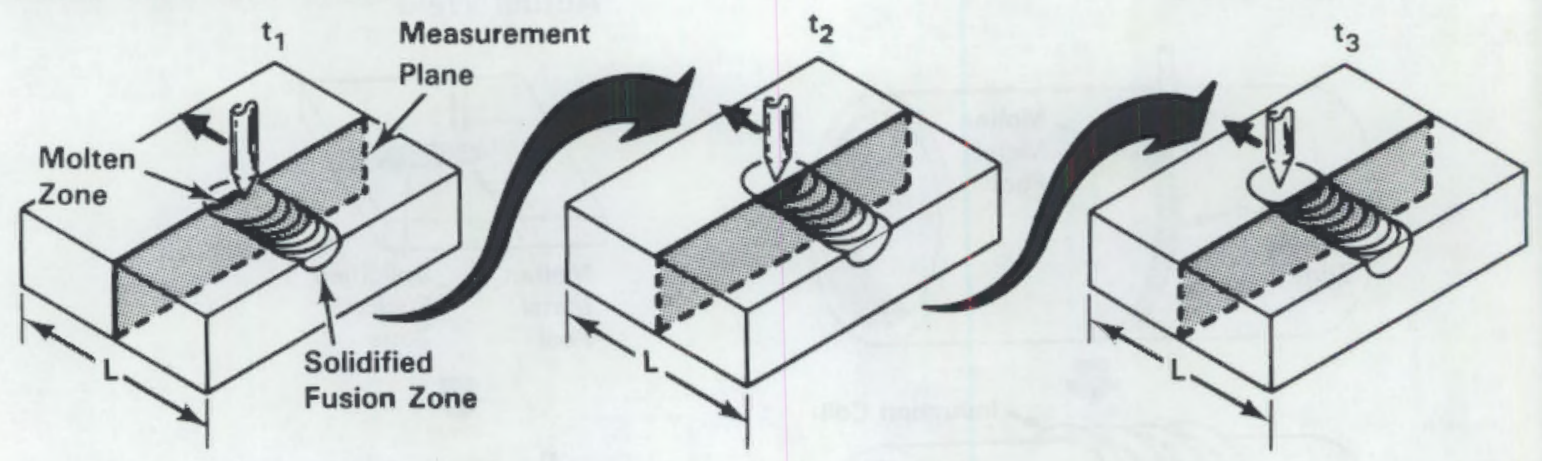

Bead-On-Plate Weld Simulation
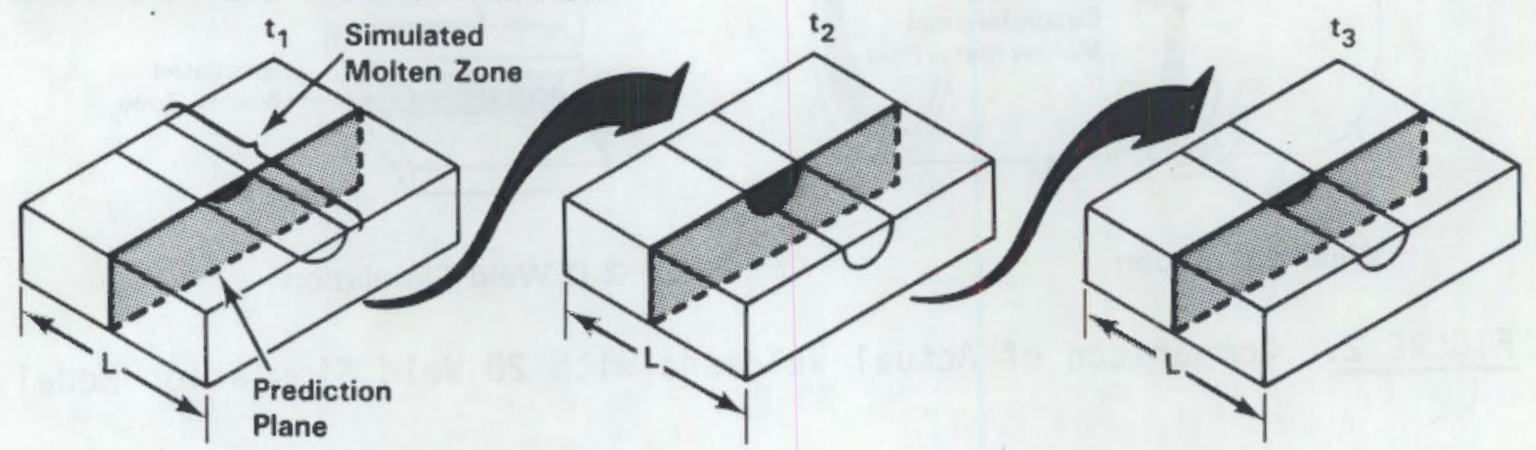

FIGURE 3. Schematic Illustrating Comparable TM History Measurement Planes in Real Plate Weld and 20 Simulation

Consequently, calculated stresses and deformations parallel to the weld axis are suspect due to unrepresented material restraint along the weld axis.

Although weld parametric studies using $2 \mathrm{D}$ weld simulation models yield useful information, realistic weld modeling requires a $3 D$ model if the effects of weld parameters on HAZ residual stresses are to be studied. Structural response to weld placement and welding procedures also requires correct 3D calculation of the stresses and deformations related to welding. Recent work at PNL has documented the effect of weld-induced deformations on HAZ microstructural evolution. (13)

In the present state of the art, 2D modeling is available, but simulating complex multipass welding situations by $3 \mathrm{D}$ modeling techniques is beyond reach. 
Thus, the short-term goal of the Hanford Site weld modeling program is to develop usefur 20 modeling procedures; the long-term goal is to develop practical 3D modeling.

PRACTICAL APPROACHES TO DEVELOPING A WELD MODEL ING CAPABILITY

Generic structural response FEM programs are commercially available and are capable of being programmed for 20 weld simulations. The generic nature of these programs results in very costly 30 weld simulations. Mahin ${ }^{(9)}$ is developing a FEM program that is specifically directed toward weld simulation with 30 modeling capabilities. It is the most complete and realistic weld-oriented FEM program we know of. Near-term Hanford Site use of this program is not possible, since it is being developed from first principles and will require years of continuing development before it is capable of handling multipass welding. More than that, it is being developed to predict all aspects of weld-related interactions, without regard for computer processing efforts. Hence, the cost of conducting parametric studies with the Mahin model will probably be prohibitive, at least from today's perspective.

Professors at several universities are developing models of arc physics or weld pool stirring phenomena. These are interesting but very limited from a practical applications point of view.

At least one major university study, that by the Goldak group, concentrates on developing highly efficient FEM programming techniques and applying these to welding problems. Major emphasis is on developing usable FEM techniques and not on experimental generation of a data base to put into model simulations. Program orientation is toward developing FEM techniques that will make 3D weld modeling feasible, ultimately for personal computers (PCs) of the future.

A practical approach to developing Hanford Site weld modeling capability in the near term can employ commercially available, general-purpose FEM programs for initial 2D modeling work. Simultaneously, and eventually superseding this, would be a collaborative effort with Goldak in developing an advanced $2 \mathrm{D}$ and 3D modeling capability. 
2D MODELING WITH ANSYS

PNL has a generic, commercially available FEM program called ANSYS installed on an Apollo computer. This highly sophisticated, state-of-the-art program is being used as the first step in developing Hanford Site weld modeling capability. This system was used by Garnish(13) to calculate weld thermal histories for stainless steel (SS) pipe girth welds under a Nuclear Regulatory Commission (NRC)-sponsored welding program.

Predicted thermal histories on the inside counterbore surfaces as a function of distance from the weld centerline have been made for 4-, 14-, and 24-in.-dia. pipes, as illustrated in Figures 4 and 5. A comparison between predicted and measured thermal histories for the first pass on the 24-in.-dia. pipe indicates reasonable agreement (Figure 5). The FEM program calculates this type of information for internal points of the pipe weld cross-section as we11.

Through-thickness isotherms are another graphical data presentation method that can be readily determined with the ANSYS system. Isotherms can be used to indicate maximum extent of thermal experiences at various regions and, from this, estimates of microstructural alterations can be inferred. This technique will be utilized to predict the development of microstructures susceptible to premature service failures.

The program is capable of displaying isotherms at designated times in the weld simulation cycle; the isotherms shown throughout this report were selected at that time in the cycle when the molten pool was at its maximum, allowing reasonable definition of the fusion zone as well as a good estimate of the maximum extent of the high-temperature isotherms. Figures 6 and 7 are illustrations of this condition during each of the first three passes on 24-in.-dia. SS and carbon steel (CS) pipe girth welds, respectively, at selected heat inputs.

Figure 8 compares calculated SS and CS isotherms for the third pass, as in Figures 6 and 7. A reasonable fusion zone for the SS case is calculated, using a heat input of $28 \mathrm{~kJ} / \mathrm{in}$. The same heat input to a CS weld results in an

Registered trademark of Swanson Analysis Systems, Inc., Houston, Pennsylvania. 


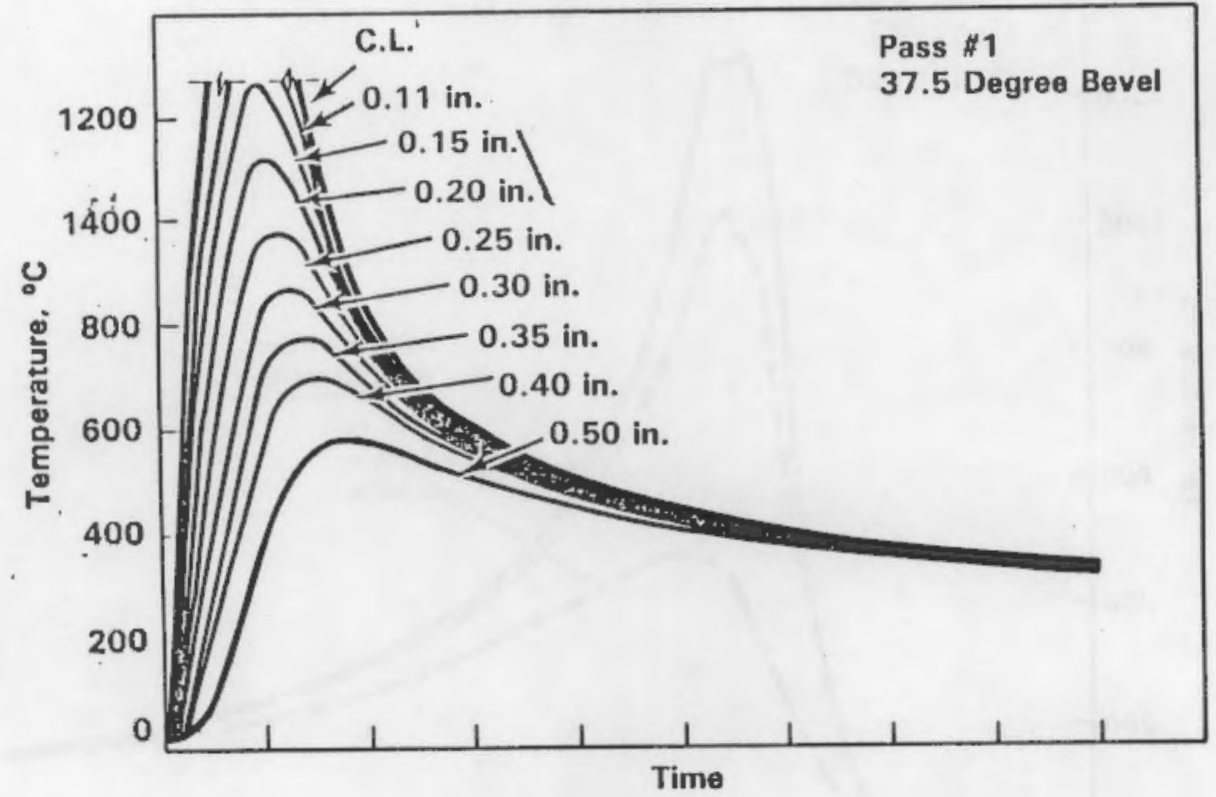

(a)

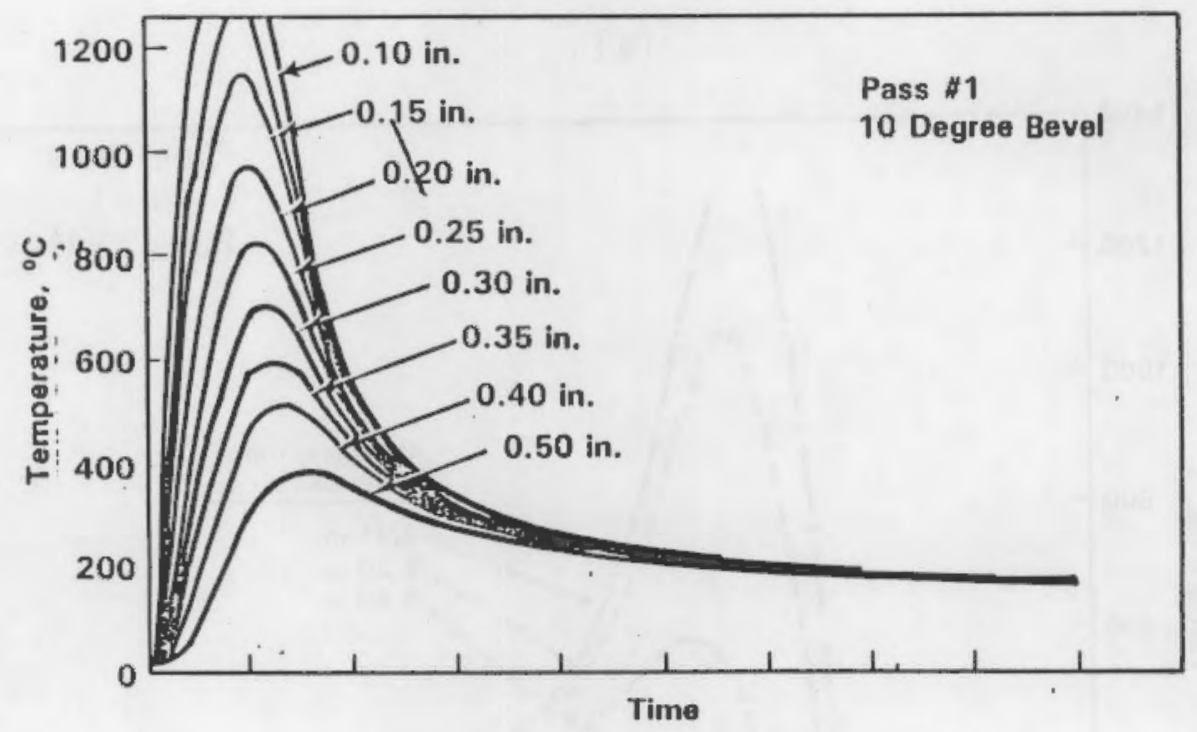

(b)

FIGURE 4. FEM-Predicted Thermal Profiles for the Inside Surface of (a) 4and (b) 14-in.-dia. Schedule 80 Type 304 SS Pipe Girth Weld 


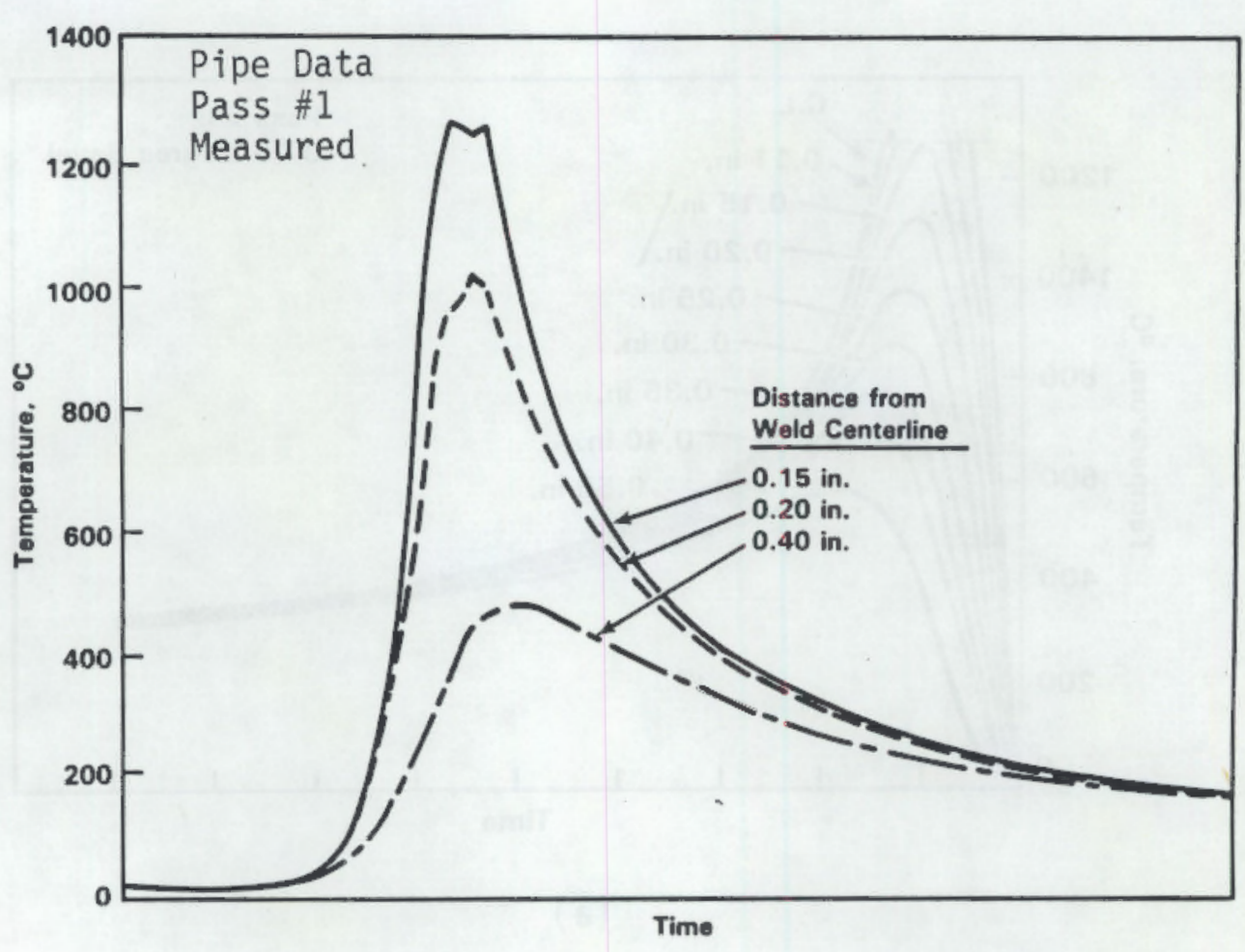

(a)

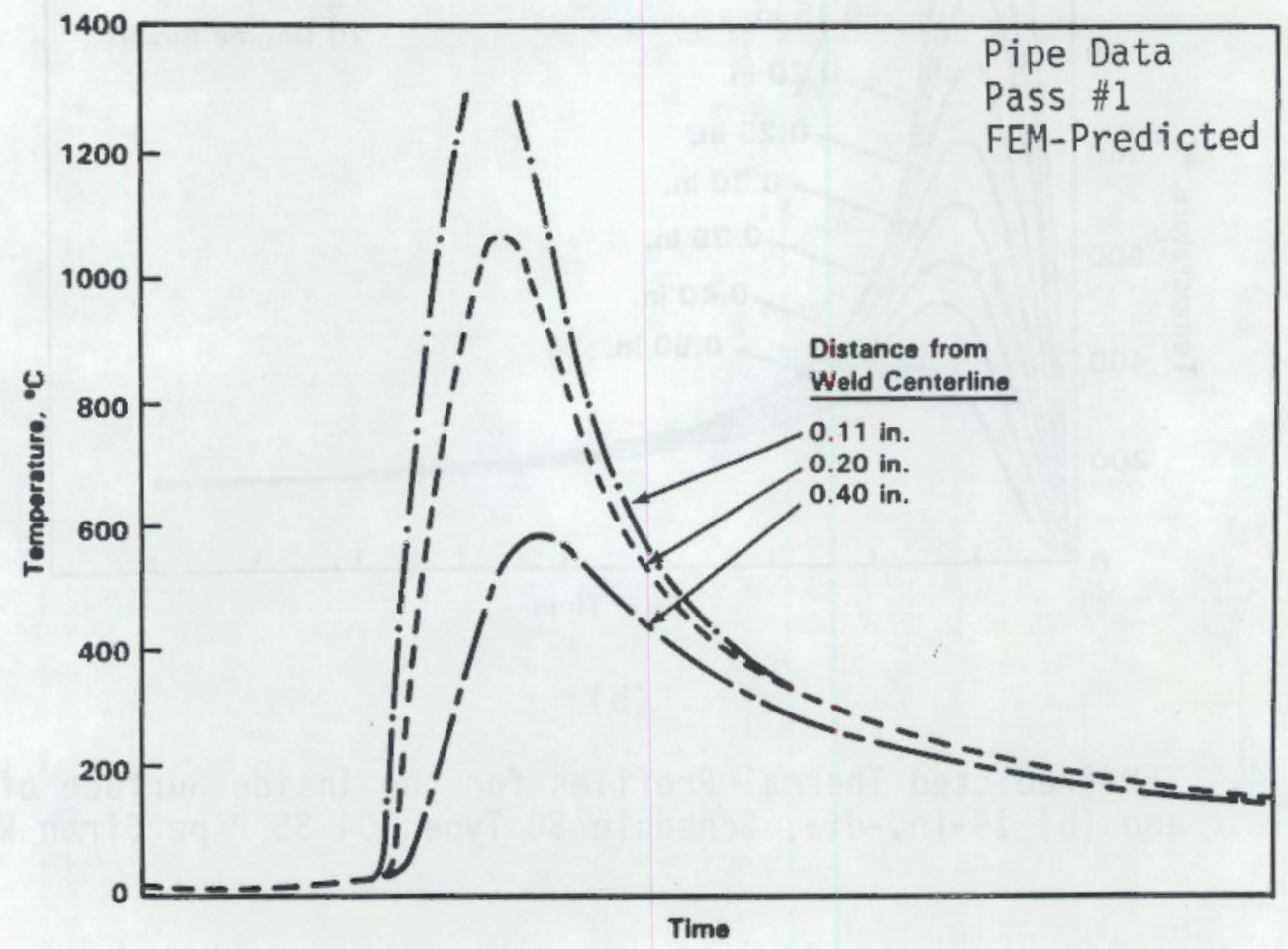

(b)

FIGURE 5. Measured(a) and FEM-Predicted(b) Thermal Profiles for the Inside Surface of a 24-in.-dia. Schedule 80 Type 304 SS Pipe Girth Weld 

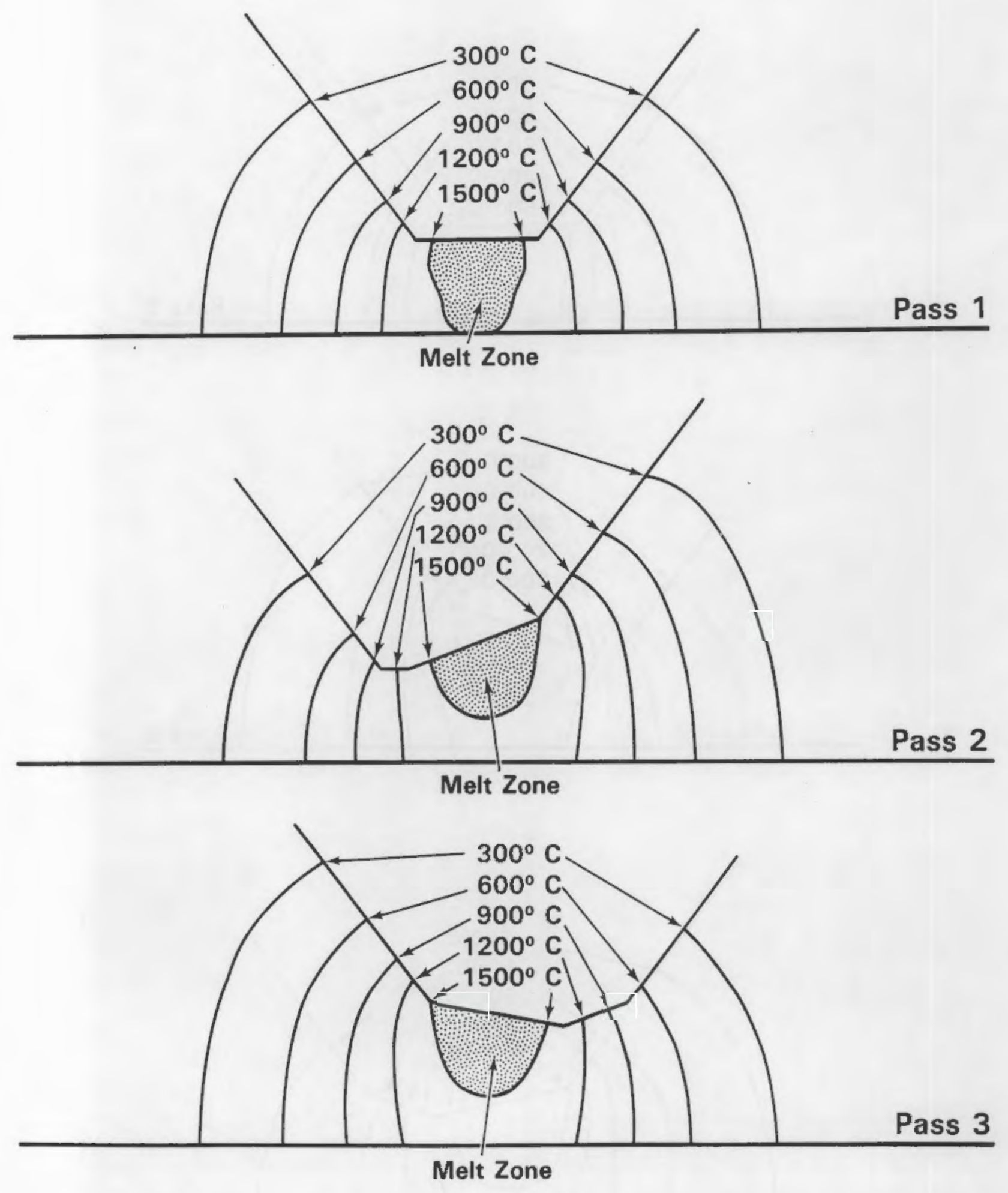

FIGURE 6. FEM-Predicted Maximum Extent of Isotherms for the First Three Passes in a 1-in.-Wall, 24-in.-dia. Schedule 80 SS Pipe Girth Weld 

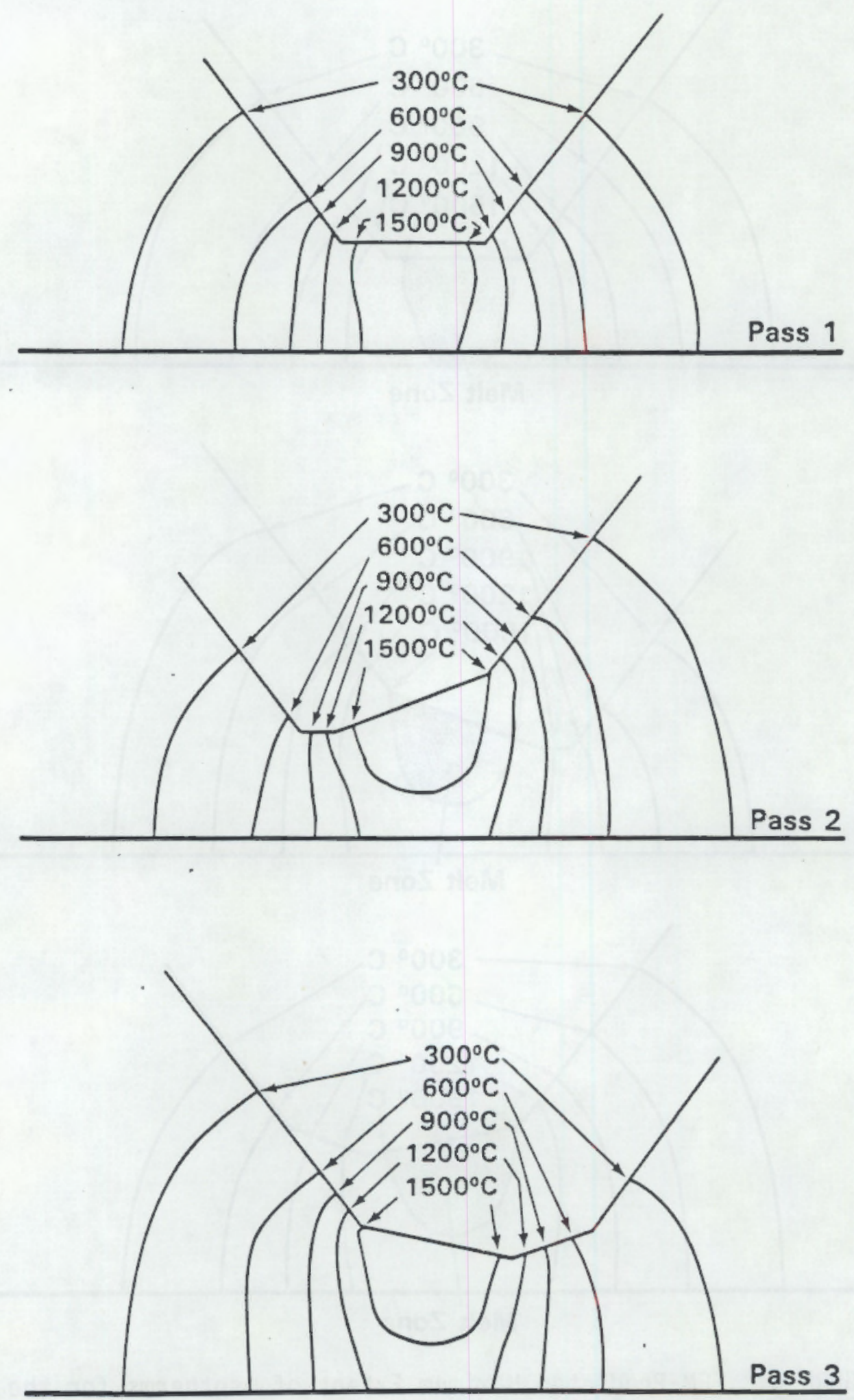

FIGURE 7. FEM-Predicted Maximum Extent of Isotherms for the First Three Passes in a 1-in.-Wall, 24-in.-dia. Schedule 80 CS Pipe Girth Weld 
Stainless at $27 \mathrm{~kJ} / \mathrm{in}$.

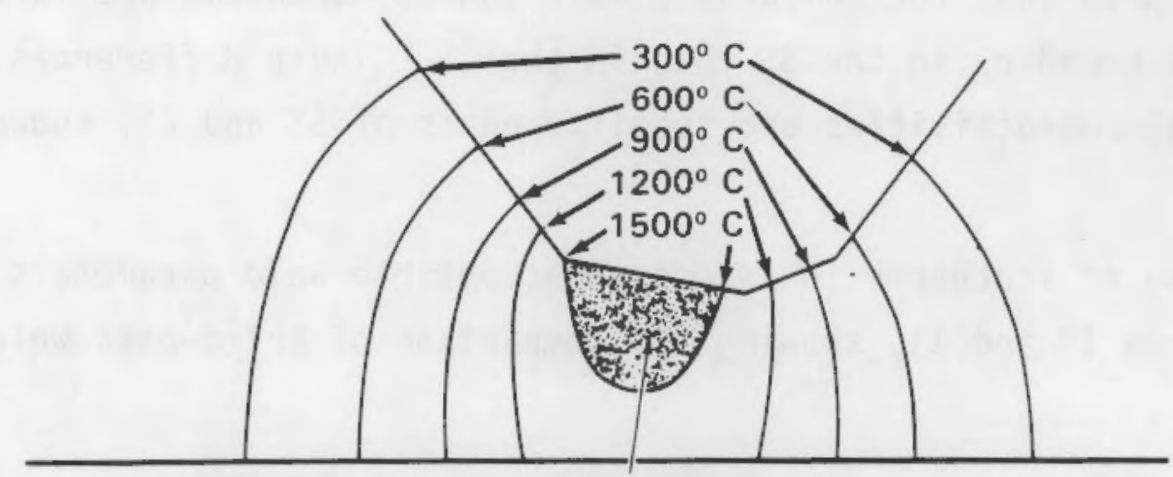

Melt Zone

Carbon Steel at $27 \mathrm{~kJ} / \mathrm{in}$.

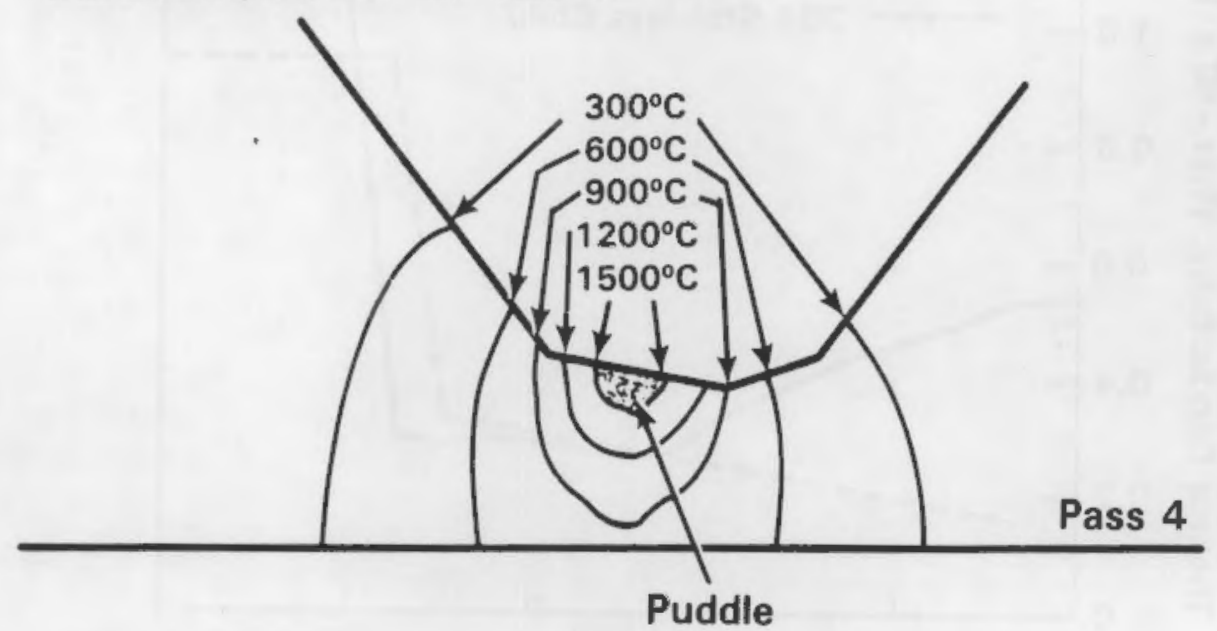

Carbon Steel at $38 \mathrm{~kJ} / \mathrm{in}$.

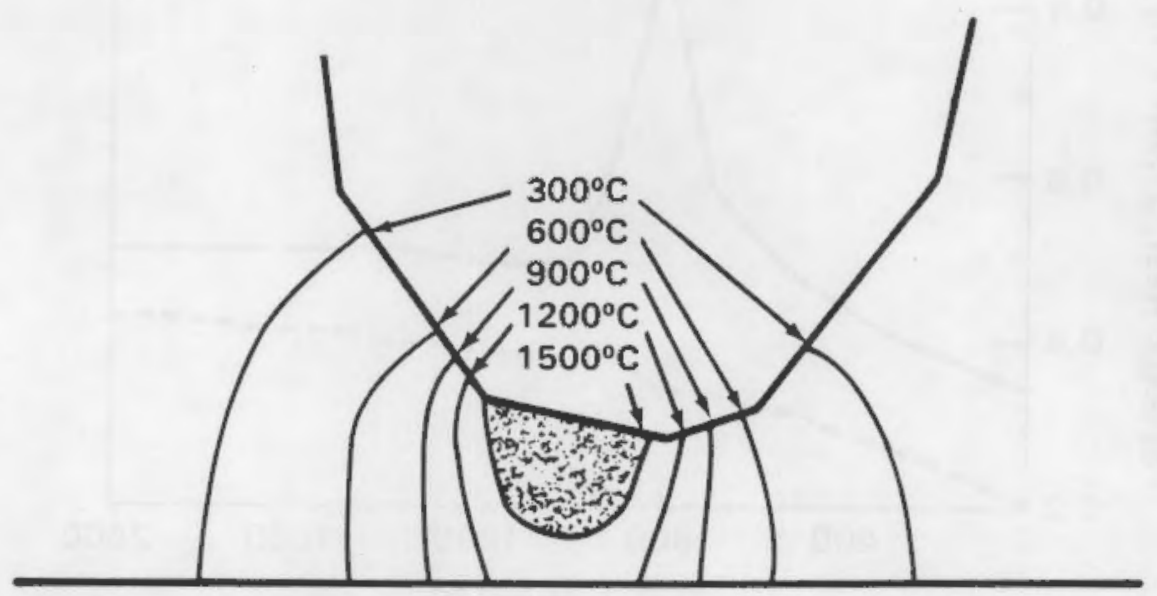

FIGURE 8. Comparison of the Effect of Heat Input on the Size of the Fusion Zone Between CS and SS 24-in.-dia. Pipe Girth Welds 
unrealistically small fusion zone. Input of $38 \mathrm{~kJ} / \mathrm{in}$. produces an acceptable CS melt zone. Note that for comparable melt zones, isotherms are farther from the molten zone boundary in the SS than in the CS. These differences arise from the thermal conductivities and specific heats of SS and CS, shown in Figure 9.

Another use of isotherms in assessing acceptable weld parameters is illustrated in Figures 10 and 11 , showing the comparison of third-pass weld heat
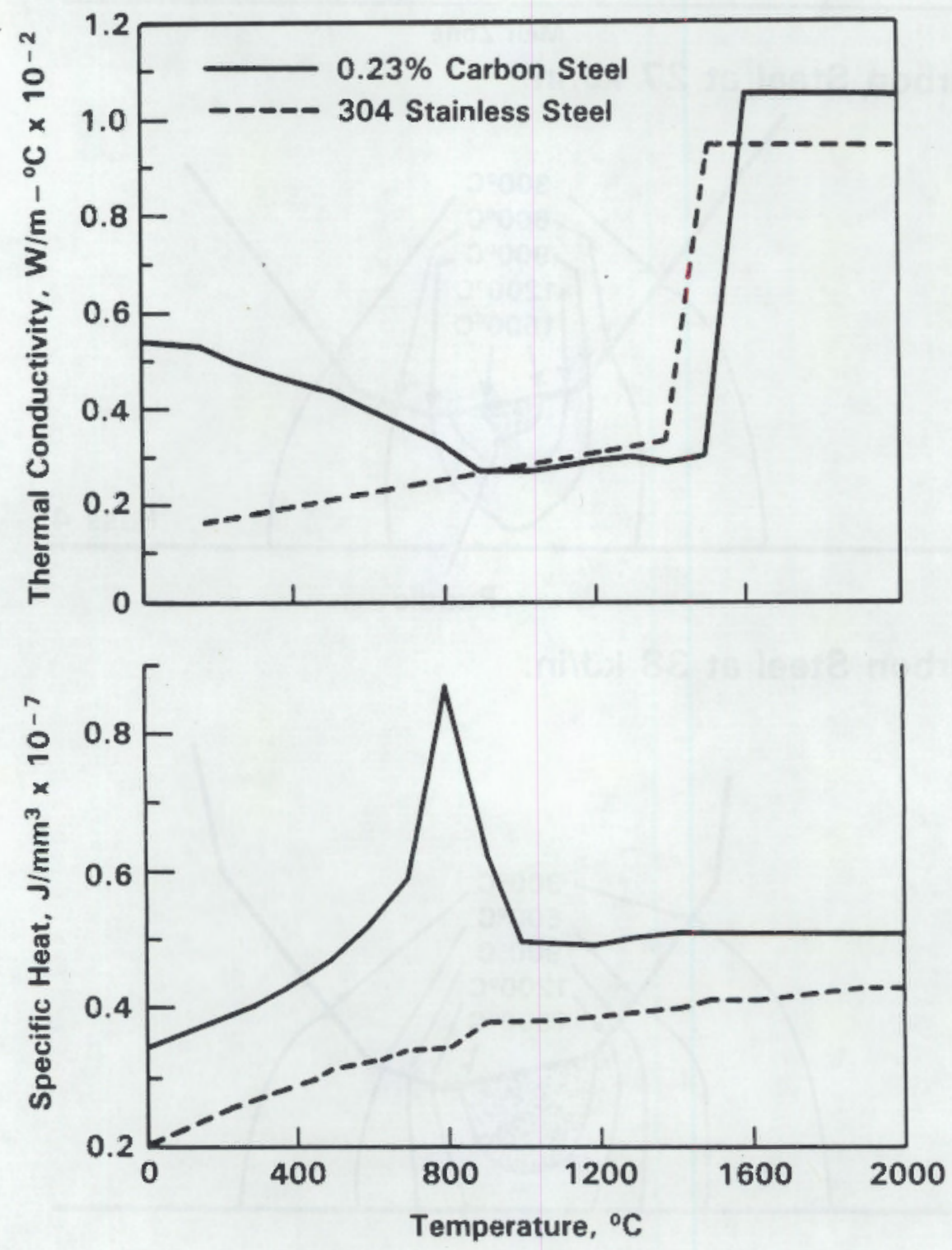

FIGURE 9. Thermal Conductivity and Specific Heat as a Function of Temperature for CS and SS 

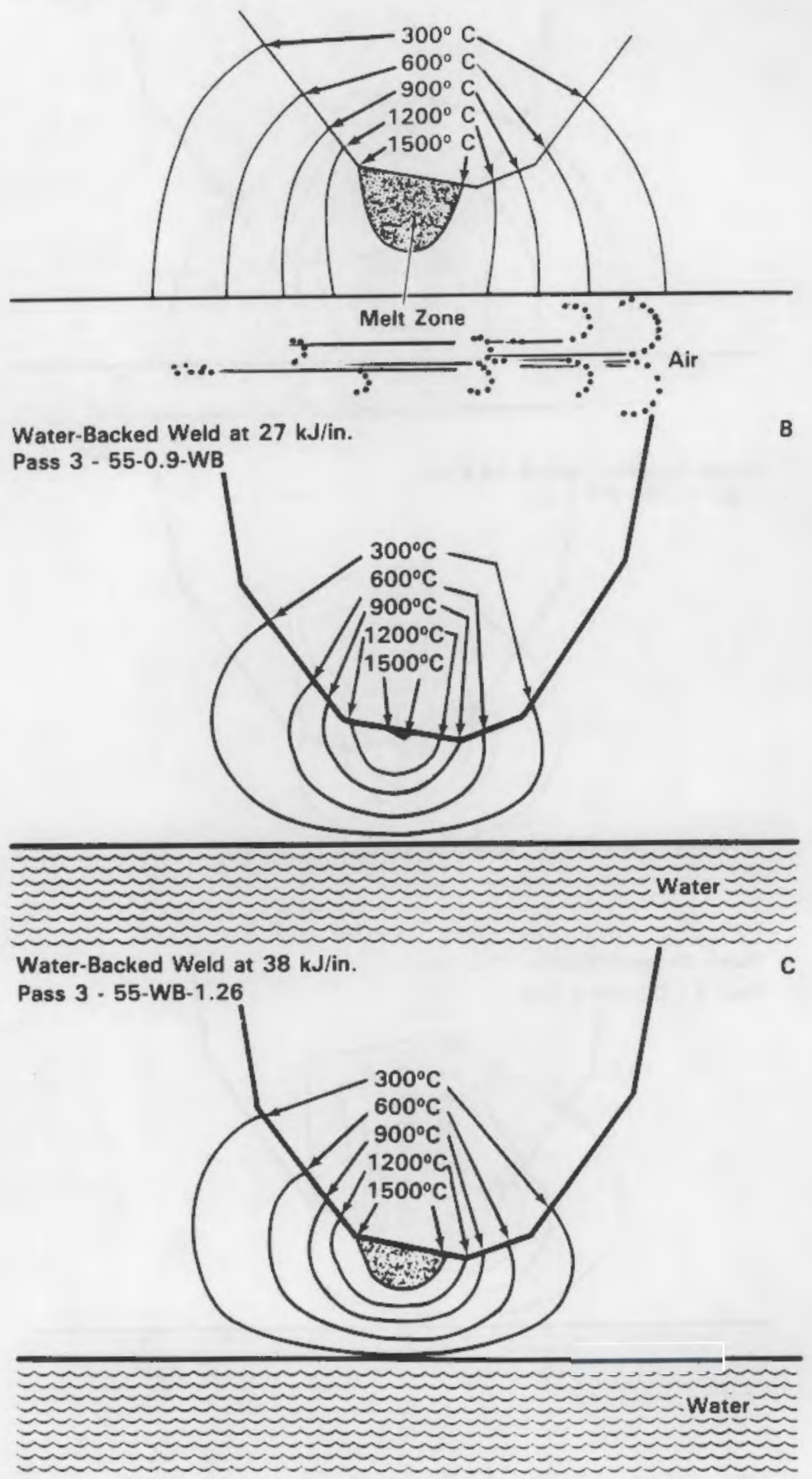

FIGURE 10. Comparison of the Effect of Air with that of Water Present in the Inside of the SS Pipe During Welding on Fusion Zone Size and Isotherm Configurations 
Air-Backed Weld at $38 \mathrm{~kJ} / \mathrm{in}$.

Pass 3 Carbon Steel - 1.26

D

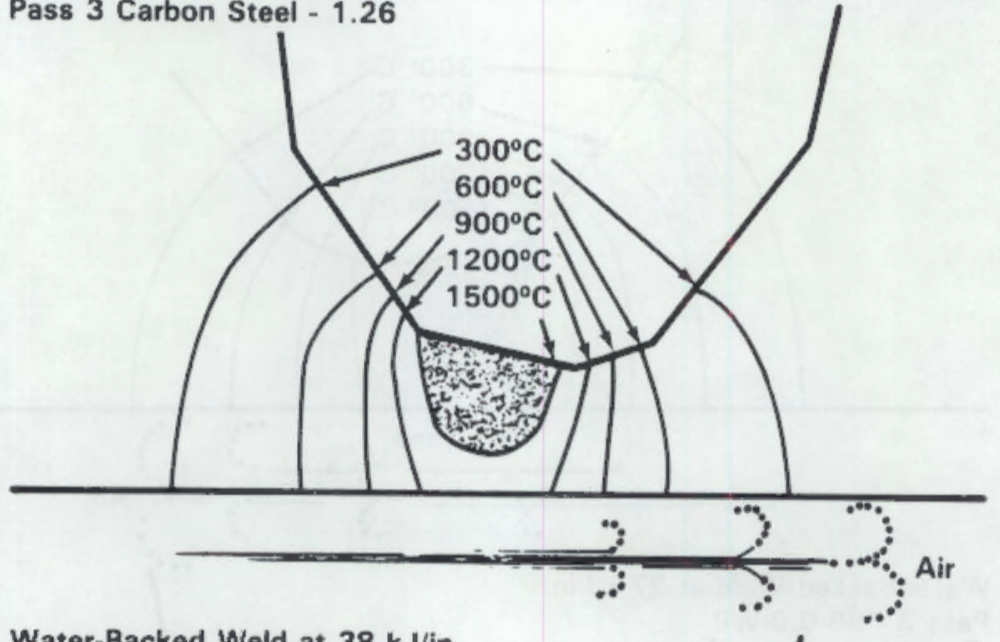

Water-Backed Weld at $38 \mathrm{~kJ} / \mathrm{in}$.

Water-Backed Weld at $38 \mathrm{~kJ} / \mathrm{in}$.
Pass $3 \cdot$ CS-WB- 1.25

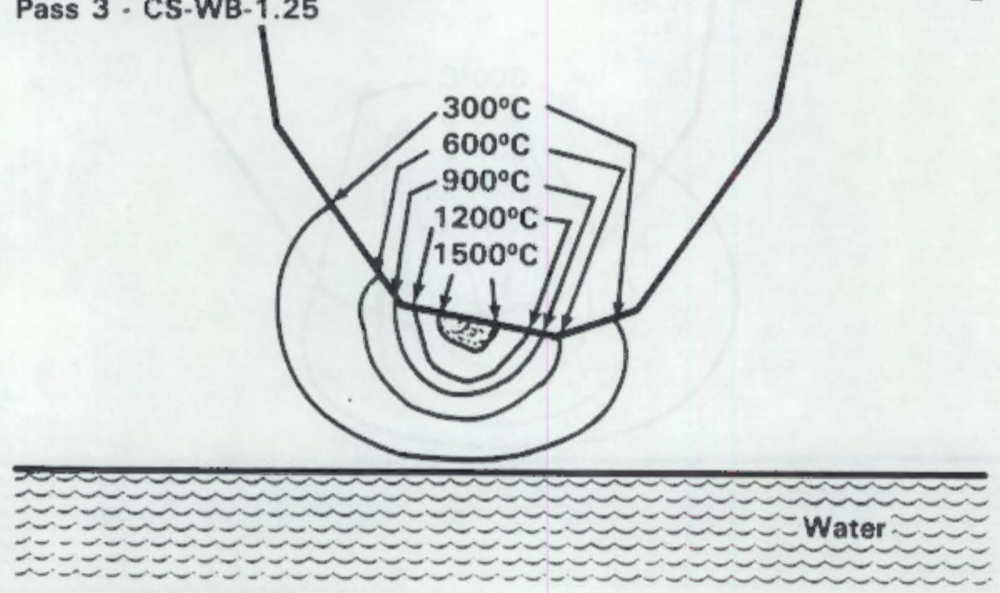

Water-Backed Weld at $53 \mathrm{~kJ} / \mathrm{in}$.

Pass 3 - CS-WB-1.754

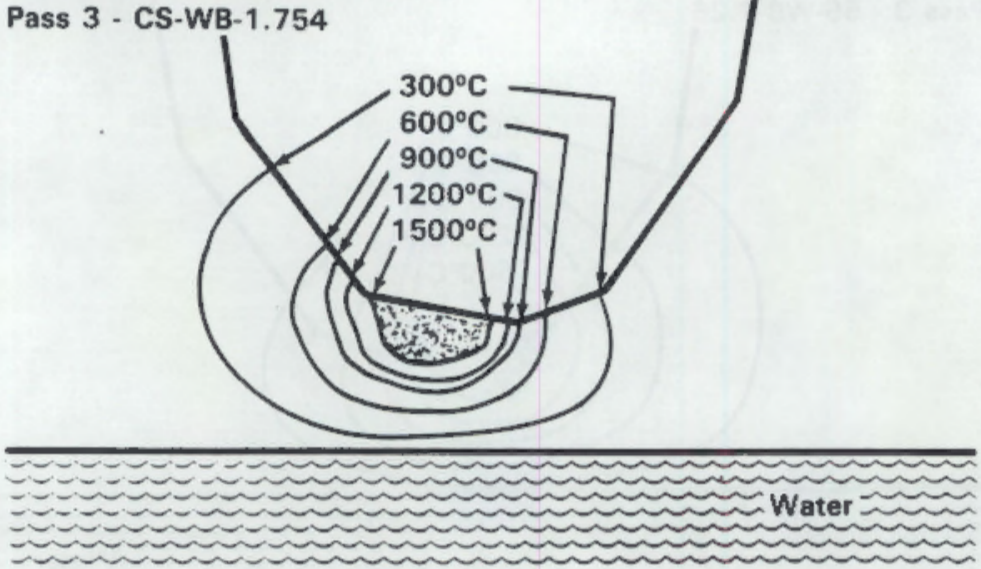

FIGURE 11. Comparison of the Effect of Air with that of Water Present in the Inside of the CS Pipe During Welding on Fusion Zone Size and Isotherm Configurations 
inputs for air-backed and water-backed welding of the 24-in.-dia. pipe for SS and CS, respectively. A water-backed heat input was determined to be acceptable when the water-backed weld fusion zone was comparable to the air-backed fusion zone; heat input approximately $10 \mathrm{~kJ} / \mathrm{in}$. over the air-backed parameter was required. Note the entirely different isotherm configurations at comparable heat inputs and fusion zone sizes.

Microstructural changes in the HAZ result from both heating and cooling and the rates of heating and cooling; these aspects are considered in a subsequent section. Here, it is only necessary to note that ANSYS is capable of exhibiting temperature and heating rate as a function of time for any position on the weld cross-section, as illustrated in Figure 12.

THE 2D AND 3D CAPABILITIES OF THE GOLDAK MODEL

The finite element weld model being developed by Professor J. Goldak at the Carleton University in Ottawa, Canada, has been selected for the Hanford

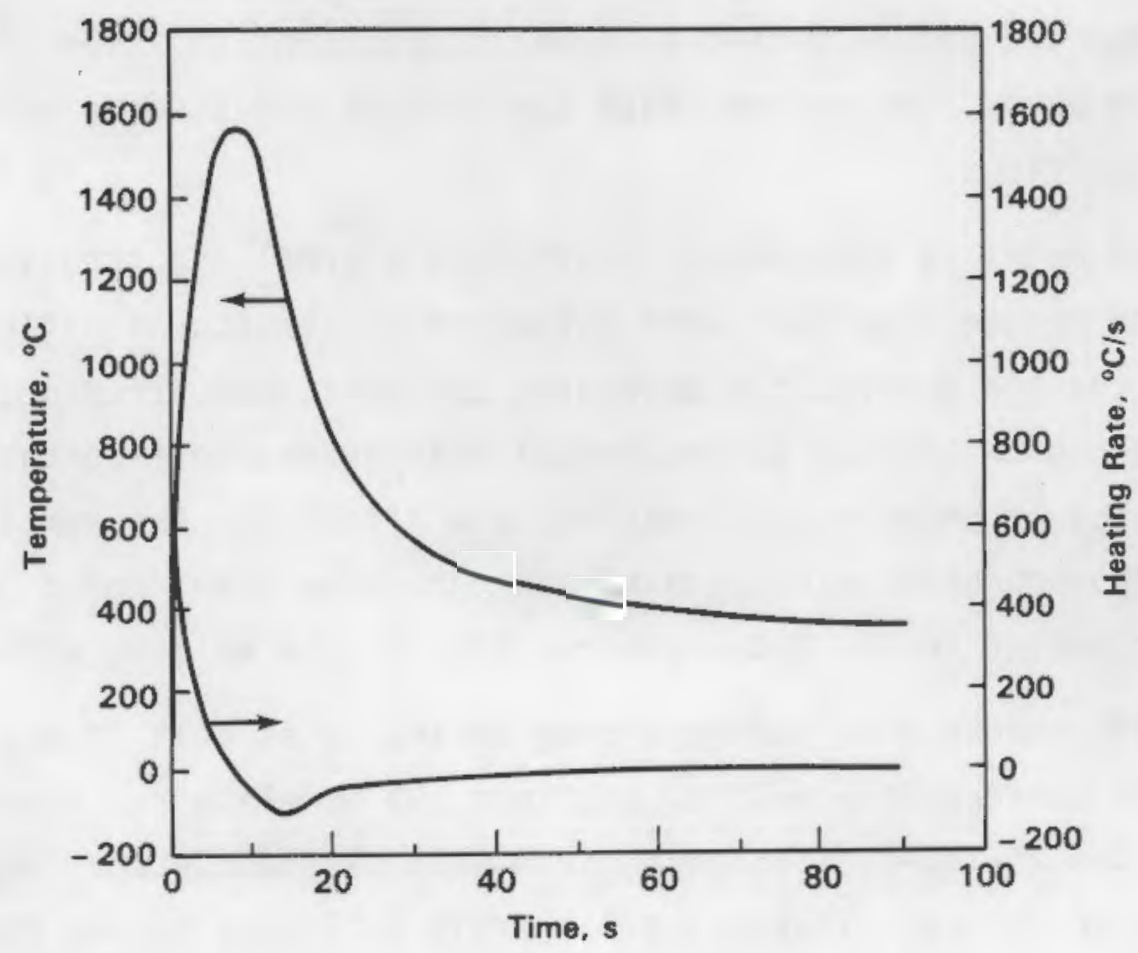

FIGURE 12. FEM-Predicted Weld Metal Heating and Cooling Characteristics 
Site program because of its potential for practical application. It is strongly oriented toward computer-programming efficiency, yet has the planned capability for treating the generic welding problem, from arc to welded structure, instead of being problem-specific to a narrow welding-research area.

In Goldak's generic weld model, portions of the welding process that are not easily represented in mathematical expressions are instead empirically estimated. Quantitative models such as arc physics can be readily superimposed onto the Goldak model once they are available. Consequently, the major work of developing software for 3D weld simulation can continue without first-principle models being available for all segments of the welding process.

Cooperative interaction with Goldak was initiated under NRC-sponsored pipe welding research which allowed PNL the use of his FEM program, presently installed on the PNL Apollo computer. Initial work with his model indicates that the program has modeling capability suitable for Hanford Site welding problems, since it has been specifically developed for treating practical cases. Its double-ellipsoid-shaped heat input source is patterned after actual weld pool shapes and can be varied to take into account the type of welding technique being used. The source shape can also be adjusted to account for filler metal additions.

The Goldak model is intended to treat both thermal and stress/deformation problems, which become important when estimates of structural deflections and residual stresses are desired for assessing as-fabricated structural integrity. Local deformations that occur during actual welding become important when the reaction kinetics of phase transformations are affected. An example of this is the deformation-induced acceleration of sensitization development in stainless steel HAZs documented in the NRC-sponsored PNL SS pipe welding work. $(13,15)$

Initial PNL checkout of Goldak's program indicates that it will be suitable for use on Hanford Site welding problems. A modeling run simulating the first pass in the 24-in.-dia. SS pipe girth weld was completed. Very good correlation, similar to that illustrated for ANSYS in Figure 5, was found between the predicted thermal history values and the experimentally determined values. His finite element program run took half an hour, while the identical problem 
run on ANSYS took almost 4 hours. This very substantial run time saving not only decreases turnaround time but run time cost as well.

Goldak's internal programming is based on program configuration improvements, not on increased computer power. Because of reduction in problemsolving time, problem complexity may be increased at no cost penalty. Improvement in run time is one of the continuing goals of Goldak's FEM experimental studies; he anticipates being able to run a complete finite element program on a personal computer in the next few years. This presents the potential for bringing the use of models out of the hands of specialists and onto the desks of working engineers, a major reason behind the decision to recommend Goldak's model for Hanford Site work.

One of the major innovations in Goldak's program, and one which is continually being developed, is mesh grading. This allows a fine mesh in areas where steep gradients are present, such as around the weld pool, and coarse meshes where little if any change is taking place, such as at the edges of the part being welded. The computational time (and thus the cost) needed for a 3D problem defined by a uniform mesh (Figure 13a) is exponentially proportional to the number of mesh elements; graded mesh, such as illustrated in Figure 13b, will result in substantial run time cost savings. (12)

The graded mesh capability is not yet fully developed. Currently, a fine mesh in the vicinity of the pool must be extended all along its projected path, even though only a small portion of the fine mesh is molten at a given instant of time. Goldak is working on a method to overcome this limitation by incorporating a transient mesh which changes as the analysis progresses. Hence, the fine mesh will only cover areas of high gradients, and will continuously change position in order to incorporate weld pool travel; this will result in further run time reductions.

\section{USER-FRIENDLY FRONT ENDS}

One major long-term goal for the Hanford Site weld modeling program is development of a user-friendly program that can be used by a welding engineer with minimal computer experience. For weld modeling to be an engineering tool instead of a scientific curiosity, the welding engineer who has a specific 


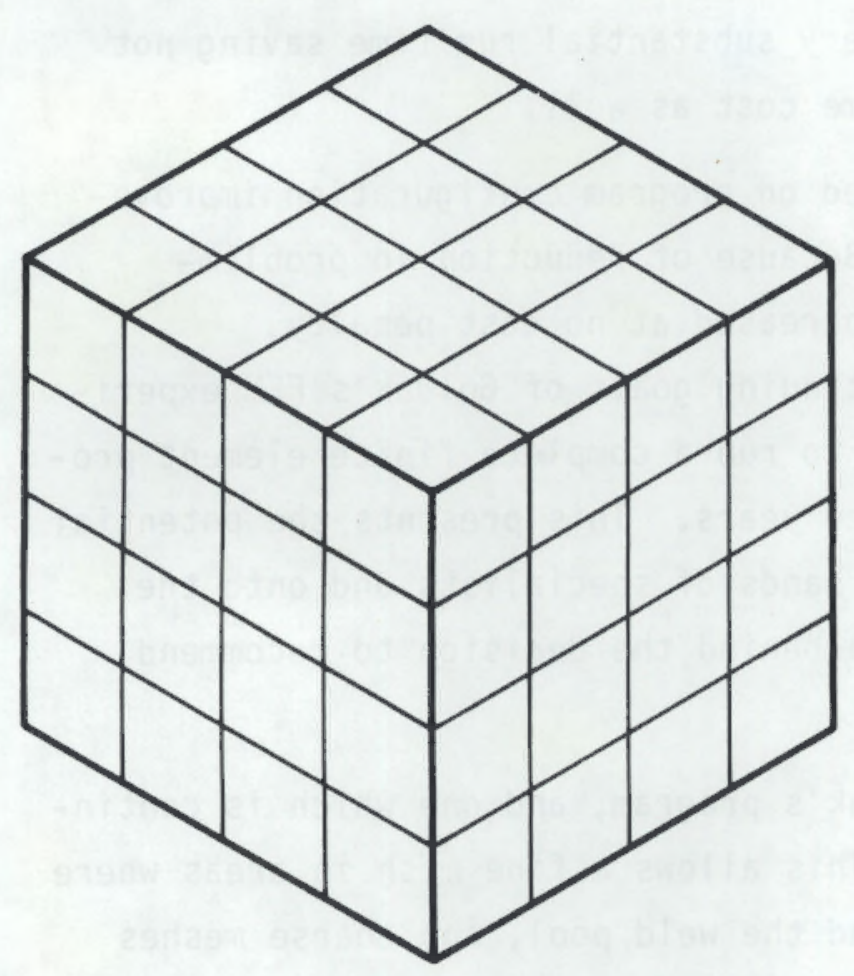

(a)

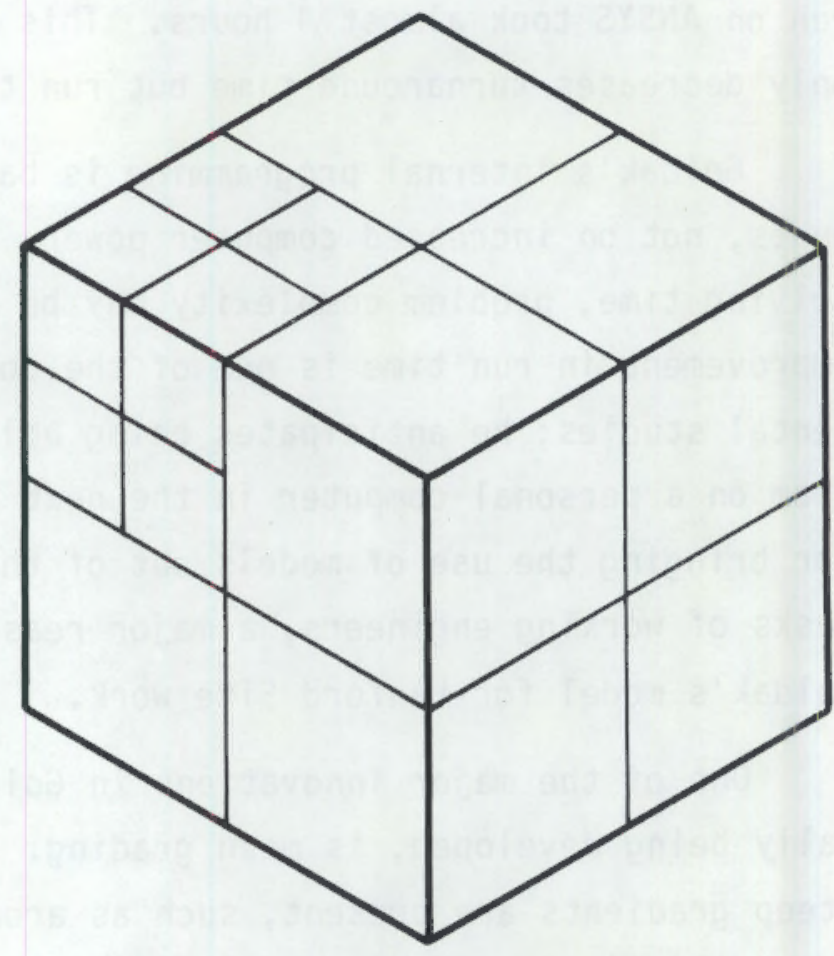

(b)

FIGURE 13. Comparison of a Uniform FEM Computation Mesh (a) and McDill's Graded Mesh (b) for Modeling a Cube

problem needs to interact directly with the weld modeling computer program. Presently, the welding engineer has to explain his problem to a finite element programmer and have the programmer set up the geometry and manipulate the program input variables to produce results, which are then discussed with the welding engineer. Proper consideration of seemingly minor process variables presents a dialogue complexity which user-friendly programs would avoid.

There are, at present, more setup problems with Goldak's model than with ANSYS because the problem definition portion of ANSYS is more user-friendly than Goldak's. This is especially true for mesh description, since ANSYS has a semiautomatic mesh generator program while each individual node in Goldak's program must be completely defined. In addition, the graphics capability of ANSYS is at present considerably more versatile than Goldak's model. 
Goldak is presently upgrading his model's graphics capability by combining a graphics program developed at Lawrence Livermore Laboratories with his existing model; he expects this to be finished in the near future. Thus it is anticipated that his model will soon have graphics capability comparable to that of ANSYS.

We are convinced that it is feasible to develop a weld modeling capability for Hanford-Site programs that will be user-friendly, although development will entail substantial planning and programming efforts. The planning stage consists of developing those types of input and output a welding engineer would want for studying welding and welded structure problems. The development of these criteria will be vitally important in establishing program usefulness and would have to be a coordinated compromise between the desires of the welding engineer and available programming capabilities.

We judge Goldak's weld-oriented model as the most promising for treating real-world weldments in a minimum of time; lack of a friendly front end on Goldak's current program is not a detriment since any program we might choose will require development of a welding-engineer-friendly front end. 



\section{TASK 2: ASSESSMENT OF WELD METAL AND HEAT-AFFECTED-ZONE}

MICROSTRUCTURAL EVOLUTION PREDICTION TECHNIQUES

\section{OBJECTIVE}

The purpose of this task is to assess techniques used in the microstructure evolution prediction methods currently available, and to determine whether the Goldak thermomechanical weld model might incorporate such procedures.

\section{INTRODUCTION}

The TM calculation model described in Task 1 is only the first step in predicting premature-failure-related material characteristics in welded structures. It is a critical first step, since microstructure development depends on TM history and, in turn, material service properties depend on microstructure. Two examples of microstructure evolution prediction schemes presently being developed are presented below.

\section{MICROSTRUCTURAL EVOLUTION PREDICTION ILLUSTRATIONS}

Bruemmer at PNL has been developing a method to predict sensitization development in the HAZ of Types 304 and 316 stainless steels. $(13,14,15)$ The work, sponsored by the NRC, combines theoretical modeling with experimental verification. The prediction of sensitization was important as a first step in predicting resistance to SCC. Increased sensitization has been related to increased SCC susceptibility.

Stainless steels become sensitized when chromium is depleted near the grain boundaries. Depletion occurs when chromium carbides grow along the grain boundaries. Growth of the carbides is energetically favorable at certain thermal exposures, but requires more chromium atoms than locally present; diffusion to the growing carbide results in localized chromium depletion zones adjacent to the grain boundaries. Chromium atoms cannot diffuse fast enough from the grain interior to prevent this depletion zone from forming. Development of the depleted zone can be calculated if the local TM history is known. 
Simple thermal history is sufficient for some calculating depletion in cases, but experimental work at PNL indicates that local deformations must be taken into account when predicting sensitization development in the HAZ. The model being developed at PNL takes into account strain as well as thermal history; it is based on theoretically modeling the phenomenon and then adjusting model results empirically until they match the experimental data base.

Ability of the present model to predict isothermal results is illustrated in Figure 14. The top portion presents the experimentally determined change in degree of sensitization as a function of isothermal hold time. The bottom portion illustrates the predicted degree of sensitization. The general agreement between experimental and predicted results is very good.

An example of the use of this model in predicting HAZ sensitization development is presented in Figure 15. The bottom graph shows the thermal history experimentally determined on a pass-by-pass basis for a 14-in.-dia. SS pipe girth weld. The top graph illustrates the predicted chromium depletion taking place during welding. The middle graph illustrates the predicted sensitization development as measured by an electrochemical technique capable of nondestructive use in the field. Figure 16 presents the post-pass predictions of sensitization development for this weld as a function of distance from weld centerline and on a pass-by-pass basis.

Direct comparison of experimental and predicted sensitization development were also made on a pass-by-pass basis for a 24-in.-dia. Schedule 80 Type 304 stainless steel pipe welded with the mechanized gas tungsten arc technique, Figure 17. Final predicted and measured values as well as form of the predicted and measured behavior shows good agreement. Results from this study suggest that reasonable predictions of microstructural development, sensitization in this case, can be usefully formulated.

Currently, weld HAZ hardness can also be predicted for some situations from the data produced by ANSYS. There are weld HAZ hardness prediction models that predict hardness as a function of base metal chemistry and HAZ cooling rate. Figure 12 has illustrated that HAZ cooling rate data are readily output by ANSYS. Bibby at Carleton University has developed a computer program that will predict local or uniform pre- and/or post-weld heating requirements based 

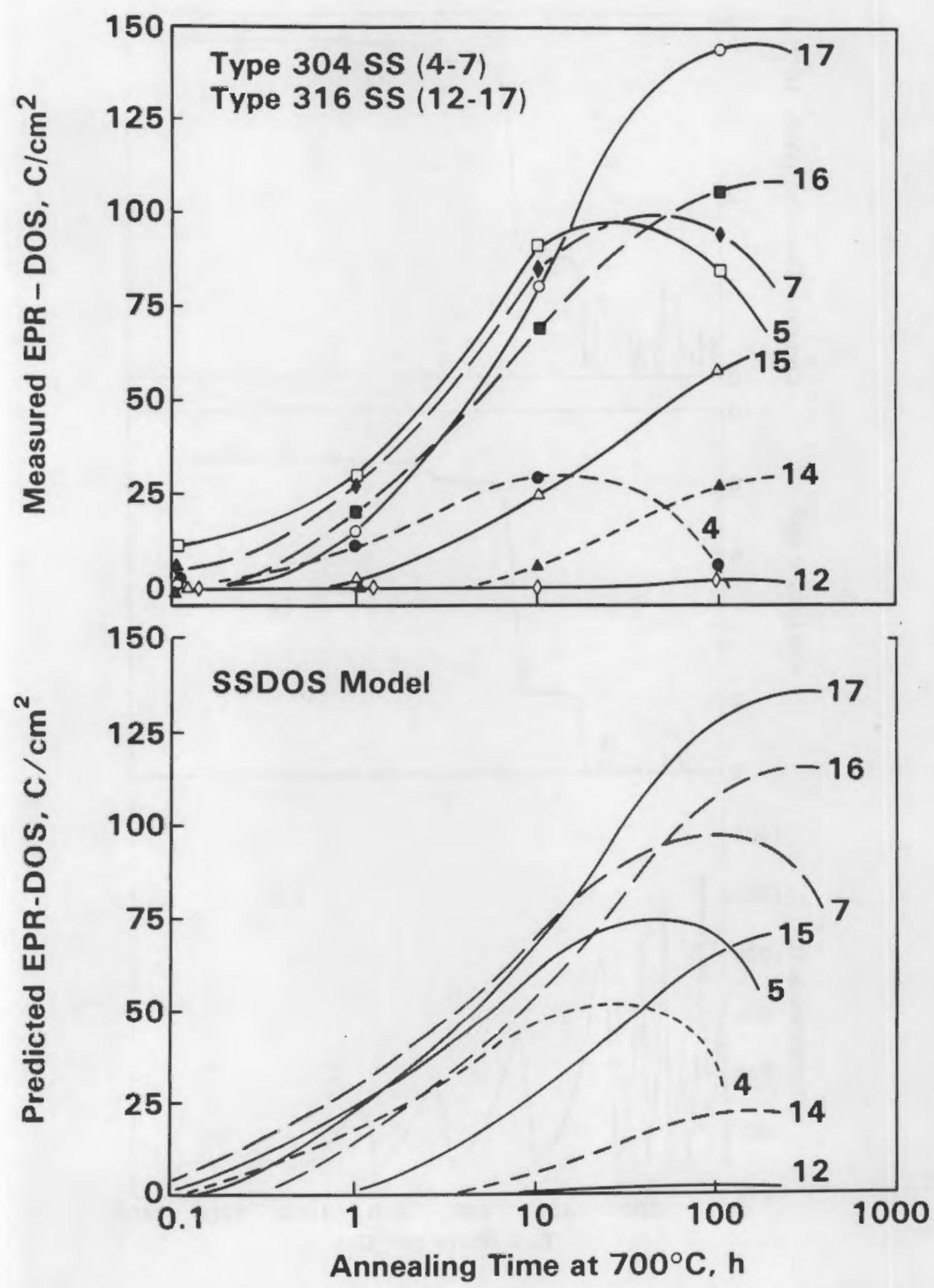

FIGURE 14. Comparison of Measured and Predicted Isothermally Induced Sensitization Development at $700^{\circ} \mathrm{C}$ in Stainless Steel 

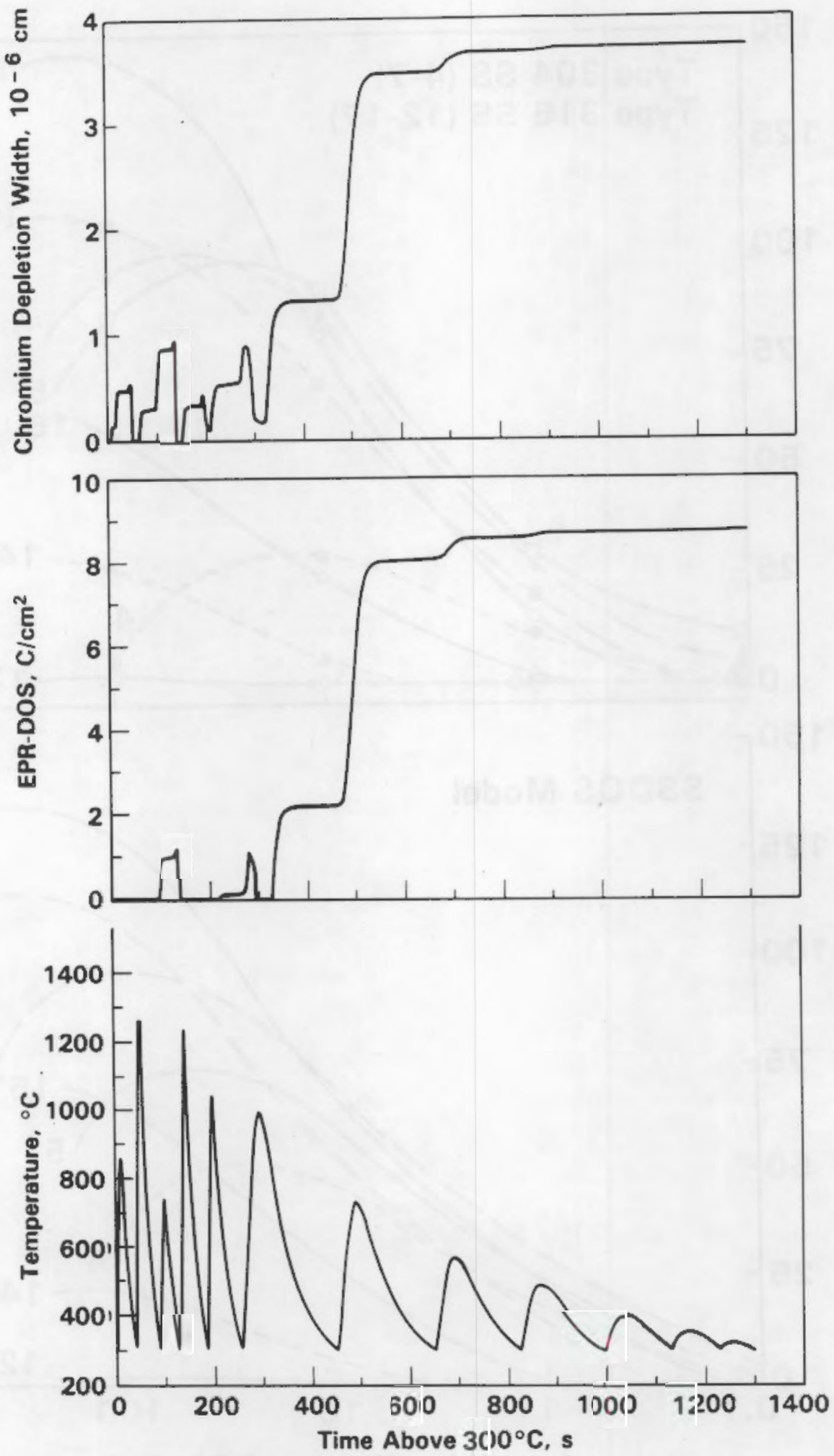

FIGURE 15. Predicted Instantaneous Sensitization Development in the HAZ on the Inside Surface of a 14-in.-dia. Schedule 160 SS Pipe Girth Weld 


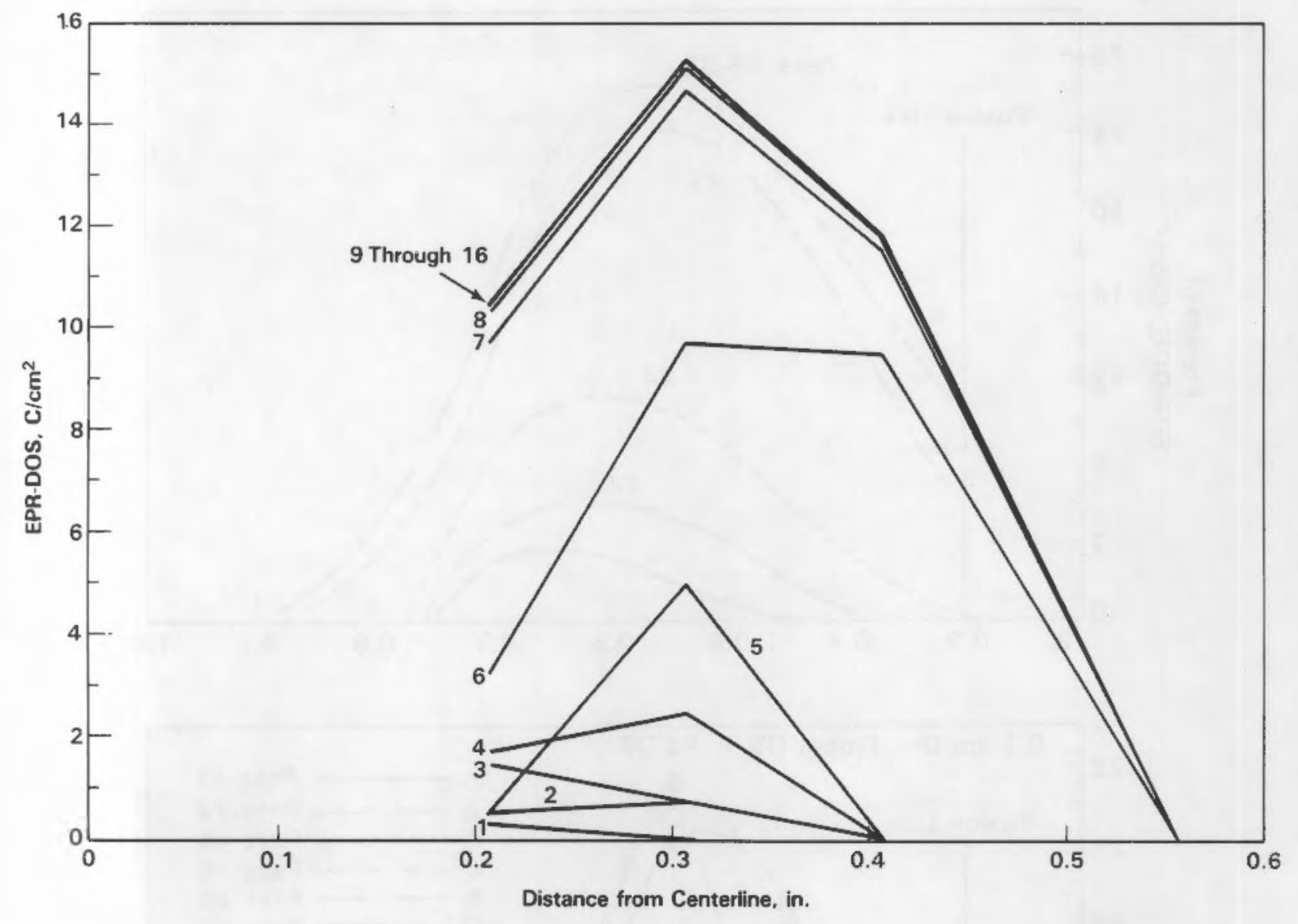

FIGURE 16. Predicted Post-Pass Sensitization Development for the HAZ on the Inside Surface of a 14-in.-dia. Schedule 160 SS Pipe Girth Weld

on HAZ cooling rates. (16) He has also developed a computer program for predicting HAZ maximum hardness as a function of welding parameters and material composition based on these same principles. (17)

Prediction of microstructural evolution could easily be integrated with a FEM-TM modeling capability, as the models require TM input easily generated by a FEM-TM model. The addition of microstructural evolution prediction capability to a FEM-TM model such as Goldak's is expected to be relatively straightforward. 


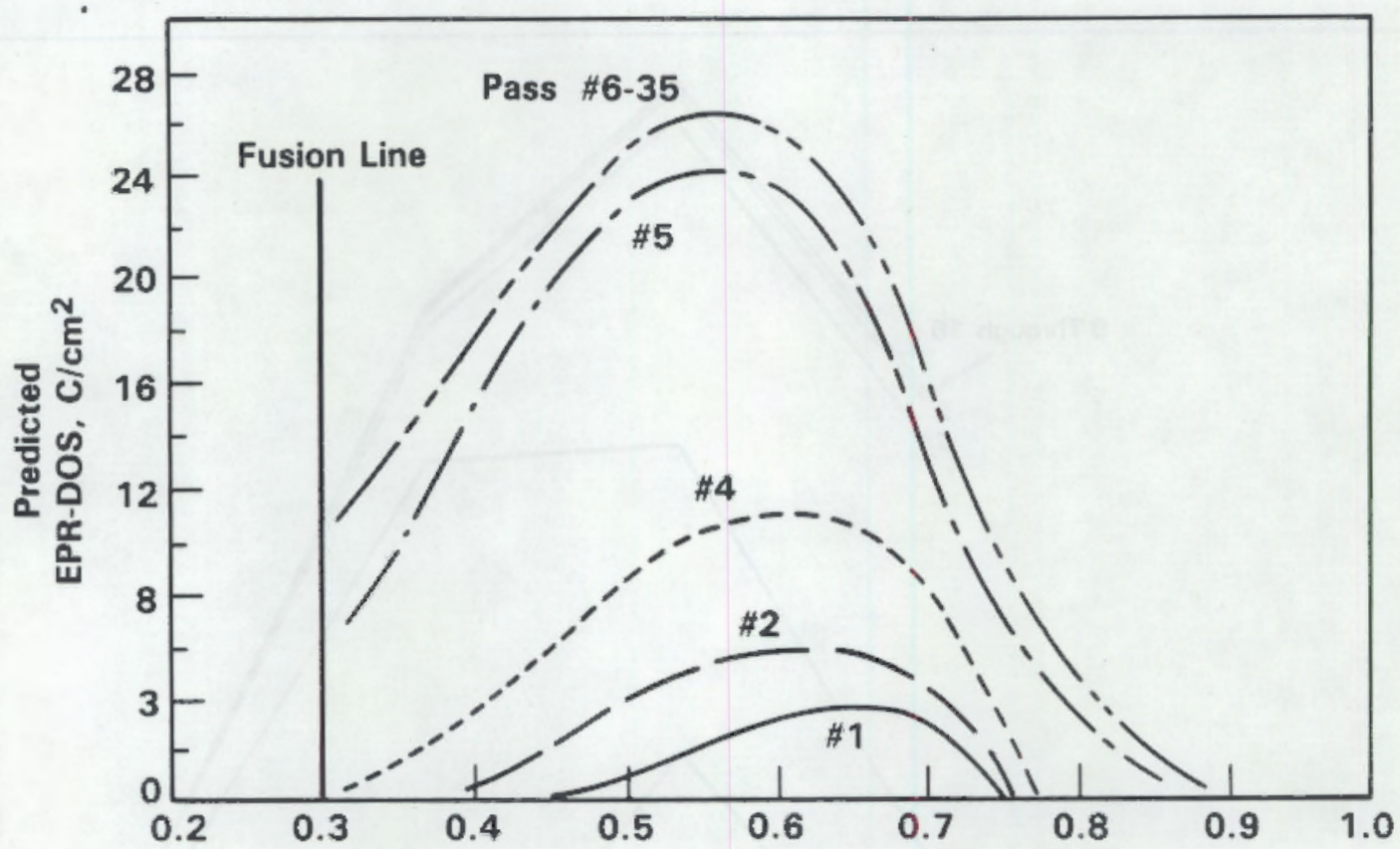

(a)

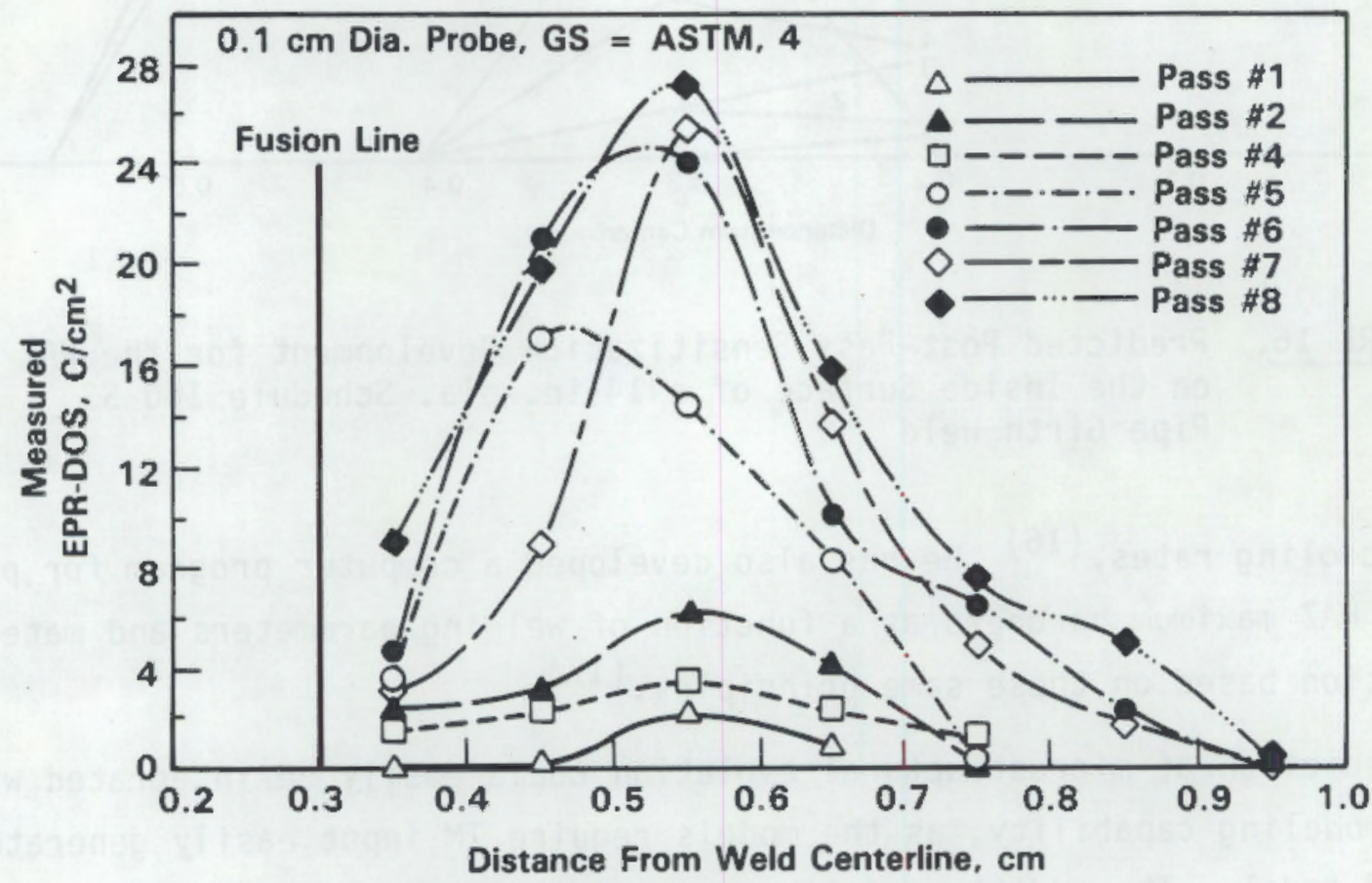

(b)

FIGURE 17. Predicted (a) and Measured (b) HAZ Sensitization Development: 24-in.-dia. SS Pipe Weld 


\section{TASK 3: PREDICTION TECHNIQUES FOR MICROSTRUCTURE-RELATED MATERIAL DEGRADATION}

OBJECTIVE

The objective of this task is to assess techniques to predict premature service failures resulting from altered material microstructure and whether these techniques can be integrated into the Goldak thermomechanical model to provide realistic evaluation of material characteristics affecting service performance.

\section{INTRODUCTION}

Relationships between microstructure and mechanical properties can be used to assess the effect of weld parameter selection. Behavioral rules such as "coarse-grained bainite generally yields low-impact energy values and is therefore detrimental," or, "sensitized stainless steels are susceptible to stresscorrosion cracking" can be incorporated with computer model decision making. The TM history result simply plots out regions where these detrimental microstructures are predicted to form. This is accomplished through use of the TM history microstructure relationships developed in Task 2. The weld parameters input to the computer model are then changed to minimize formation of detrimental microstructures.

\section{EXAMPLE MECHANICAL PROPERTY PREDICTIONS}

Correlation between sensitized SS and susceptibility to SCC can be used to predict potential premature weld HAZ failure regions. The calculated 24-in.-dia. pipe girth weld isotherms illustrated in Figure 6 will be used to identify susceptible regions and how they change on a pass-by-pass basis. Sensitization development regions will be defined as bounded by the 600 and the $1000^{\circ} \mathrm{C}$ isotherms. Any region falling below $600^{\circ} \mathrm{C}$ is unaffected by the weldinduced heat; any region above $1000^{\circ} \mathrm{C}$ is considered to experience carbides dissolution, or "healing." Figure 18 uses these empirical rules to predict microstructure evolution in the first three passes of a 24-in.-dia. SS pipe girth weld. The left-hand set of plots are the same isotherms presented in Figure 6 . The second set of plots illustrate the regions of sensitization development and sensitization healing associated with each individual pass. 

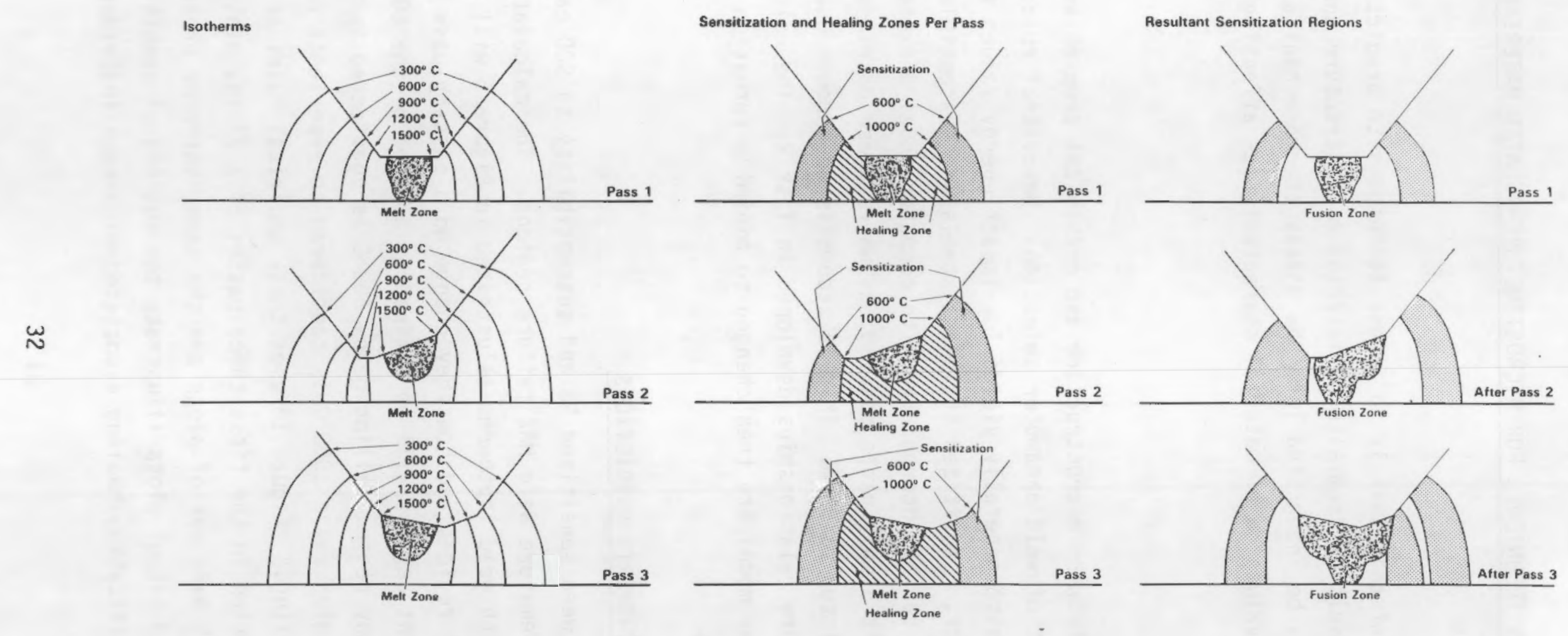

FIGURE 18. Prediction of Sensitization Development Regions in 24-in.-dia. SS Pipe Girth Weld from FEM-Predicted Isotherms 
The third set of plots illustrates the composite effect of each succeeding pass and resultant regions of sensitization susceptible to SCC. Computer simulation studies can readily assess the effects of welding parameter variation on resultant SCC susceptibility even in complex, multipass situations.

Another example of using empirical modeling techniques to predict detrimental microstructures is in the area of carbon steel nuclear pressure vessel HAZ material. A study of shielded metal arc welding (SMAW) parameters on ferritic, low-alloy steels has recently been published by J. N. Clark. $(18,19,20,21)$ He employs results from an experimental weld characterization program to develop empirical relationships used to minimize coarse-grained bainite in the HAZ of multipass welds. The prediction program was developed for $\mathrm{Cr}-\mathrm{Mo}-\mathrm{V}$ steel, in which the presence of coarse-grained bainite promotes stress-relief cracking during post-weld heat treatment and creep-promoted cracking during long-time service.

Coarse-grained bainite in the HAZ near the fusion line results from the early passes. These large bainitic grains can be refined during subsequent passes if the welding parameters are carefully selected. The rationale on which Clark based his weld parameter prediction model was:

1. minimize the formation of coarse-grained bainite in the first layer HAZ by using low-heat-input-weld passes

2. maximize the grain refinement potential of the second layer by using high-heat-input weld passes.

Regions of both coarse- and fine-grained bainite are normally present at ambient temperature in the HAZ of welded $\mathrm{Cr}-\mathrm{Mo}_{\mathrm{O}} \mathrm{V}$ steel. Coarse-grained bainite represents the microstructure region nearest the fusion line while fine-grained bainite is present in the next HAZ microstructural region. Coarse- and finegrained bainite are low-temperature transformation products of large- and small-grained austenite, respectively. Austenite is the high-temperature phase, stable from approximately $1330^{\circ} \mathrm{F}\left(720^{\circ} \mathrm{C}\right)$ to the melting point of steel; austenite transforms to bainite upon cooling. First-weld-layer HAZ coarsegrained bainite can be transformed to fine-grained bainite during welding of the second layer if the coarse-grained region of the first-layer HAZ 
experiences conditions that produce fine grains in the second-layer HAZ. Thus, coarse-grained bainite may be refined to a smaller-grained transformation product by controlling the heat input of subsequent weld passes.

The first step in developing a model prediction scheme for minimizing coarse-grained bainite in multipass welds is to determine the temperature boundary for austenite formation and then separate this region into a coarsegrained bainite formation regime and a fine-grained bainite formation regime. The temperature range where austenite is stable in the HAZ can be determined from open literature phase transformation data; it extends from the fusion line to the A3 temperature, see Figure 19. Defining the coarse and fine grain formation regions presents a more difficult problem unless continuous cooling phase transformations data are available. Clark experimentally determined this temperature boundary to be approximately $1200^{\circ} \mathrm{C}$, through a combination of metallography and theoretical calculations. He also determined relationships between the coarse- and fine-grained HAZs, welding parameters, and weldelectrode sizes through metallographic examinations of many specimens prepared under a large study of experimental welds.

These empirically determined relationships allowed Clark to develop a model that predicted multipass grain refinement as a function of real-world welding variables such as welding current and voltage, electrode size, electrode burn-off rate and weld bead spacing. These variables were related with simple nomographs that could be used on the shop floor during welding/repairing to determine appropriate welding parameters for each weld pass. (Welders were required to demonstrate adherence to these variables on practice sections before welding/repairing the actual components.)

An example of predicting the presence and extent of coarse-grained bainite can be illustrated using Clark's formation rules and the CS isotherms presented in Figure 7. The rules are that coarse-grained bainite is formed between the fusion boundary and the $1200^{\circ} \mathrm{C}$ isotherm and that grain refinement of this coarse-grained bainite takes place between 1200 and $900^{\circ} \mathrm{C}$. Figure 20 illustrates the effect of these prediction rules for the first three passes of a 24-in.-dia. pipe girth weld. The first set of plots presents the same isotherms shown previously in Figure 7 . The second set of plots illustrates the 


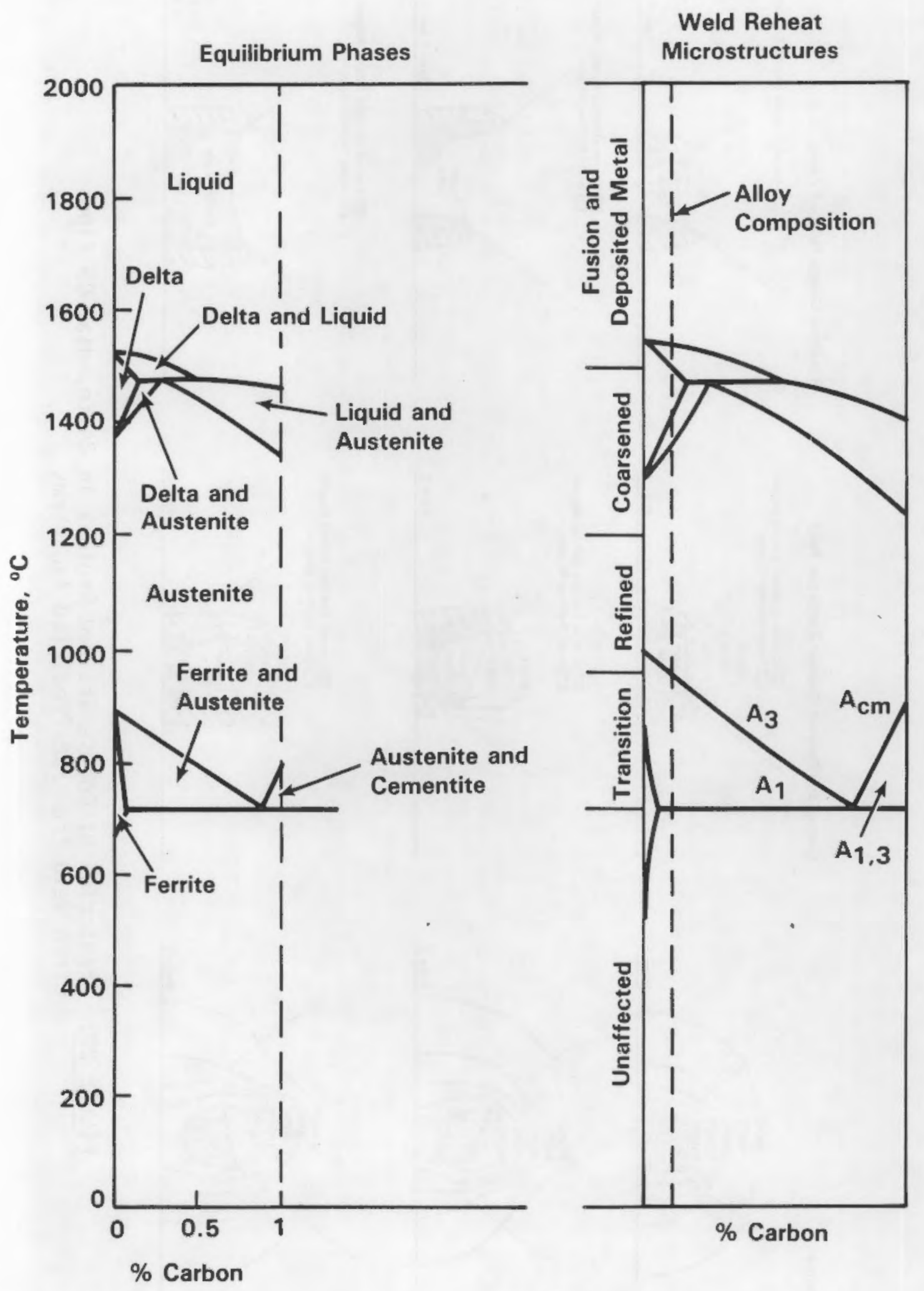

FIGURE 19. Relation of CS Weld Reheat Zones to Equilibrium Phases Present at Reheat Temperatures 
Isotherms
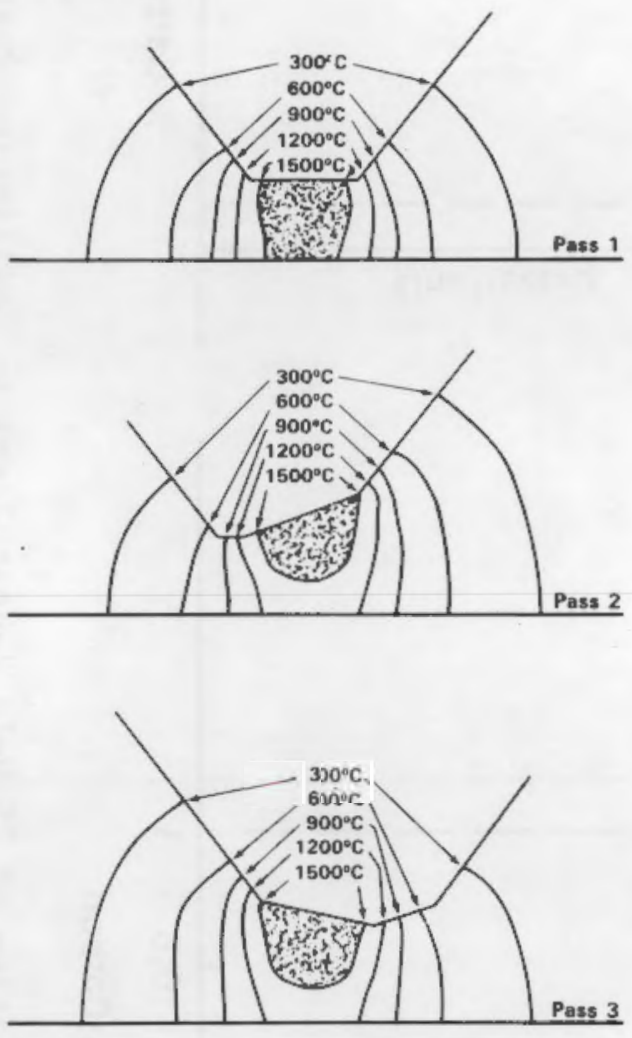

Coarse and Refined Grained Zones per Pass
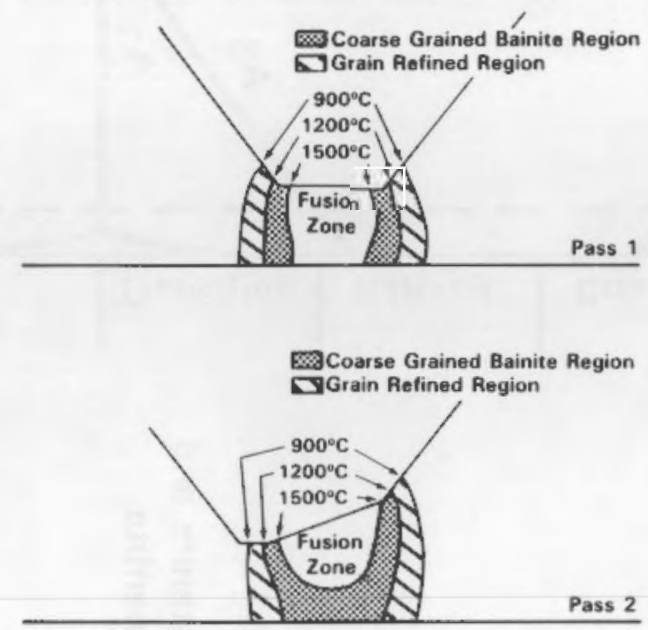

Pass 2

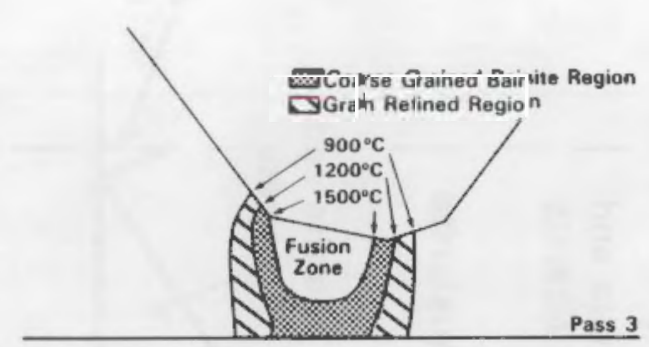

Resultant Coarse Grained Zones

ळroarse Grained Báinite Region

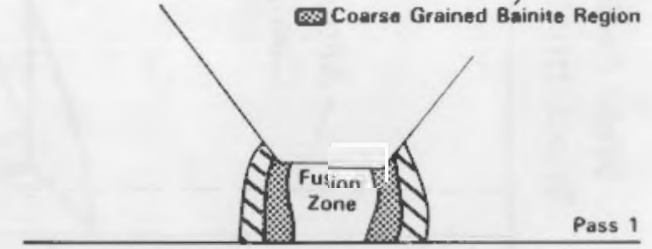

网 Coarse Grained Bainite Region $\square$ Grain Refined Region
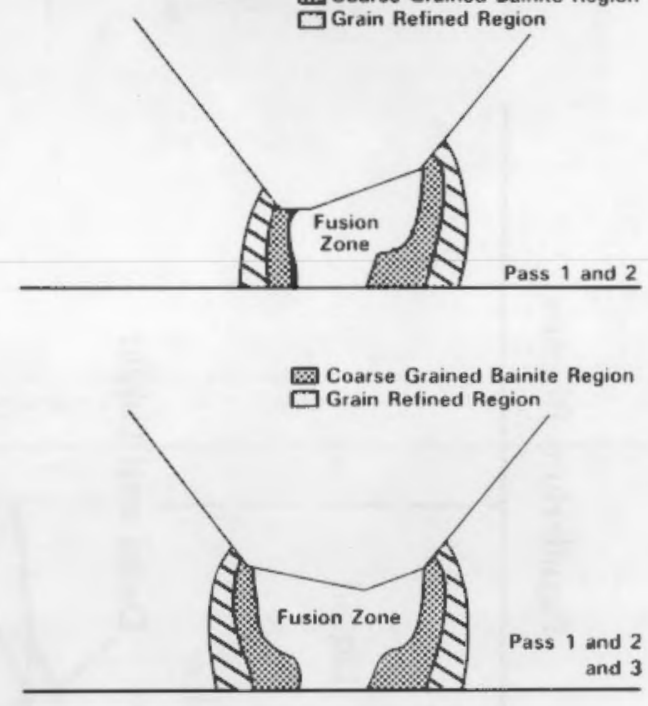

FIGURE 20. Prediction of Coarse-Grained Regions in 24-in.-dia. CS Pipe Girth Weld from FEM-Predicted Isotherms 
coarse-grained bainite and fine-grained regions formed during each pass. The third set of plots illustrates the cumulative effect of each weld pass on the resultant development of the coarse-grained bainite region.

The effect of substantially changing weld parameters after the first pass is shown in Figure 21. The heat input of the second through the fourth passes was substantially reduced, as can be seen by comparing the fusion zone sizes exhibited in the first set of plots, Figures 20 and 21 . These low heat-input passes represent placement of a "buttered" layer of weld metal over the weld groove surface, similar to the repair technique investigated by $\mathrm{Clark}$. The second set of plots in Figure 21 illustrate the coarse-grained bainite and fine-grained regions formed during low-heat-input welding. The third set of plots illustrated the composite effect of each sequential pass. It is obvious that the region of coarse-grained bainite extending to the inside surface of the pipe is greatly reduced and that careful selection of the butter-layer parameters would eliminate the inside-surface coarse-grained bainite region entirely.

Still another example of empirical correlations that could be easily computerized is illustrated in Figure 22. (22) The microstructural characteristic under study here was hardness but could as easily have been another microstructural constituent. The aggressive environment studied was hydrogen sulfide but it could be any aggressive environment for any specific material desired, providing that information relating behavior to microstructure is available and that microstructural evolution can be traced. 


\section{Isotherms}

Coarse and Refined Grained Zones Per Pass
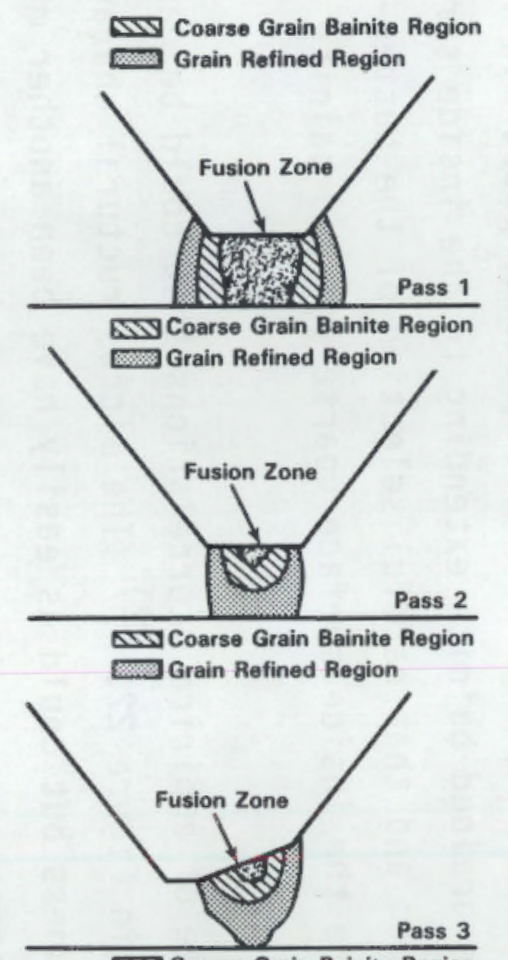

0 Coarse Grain Bainite Region Grain Refined Region
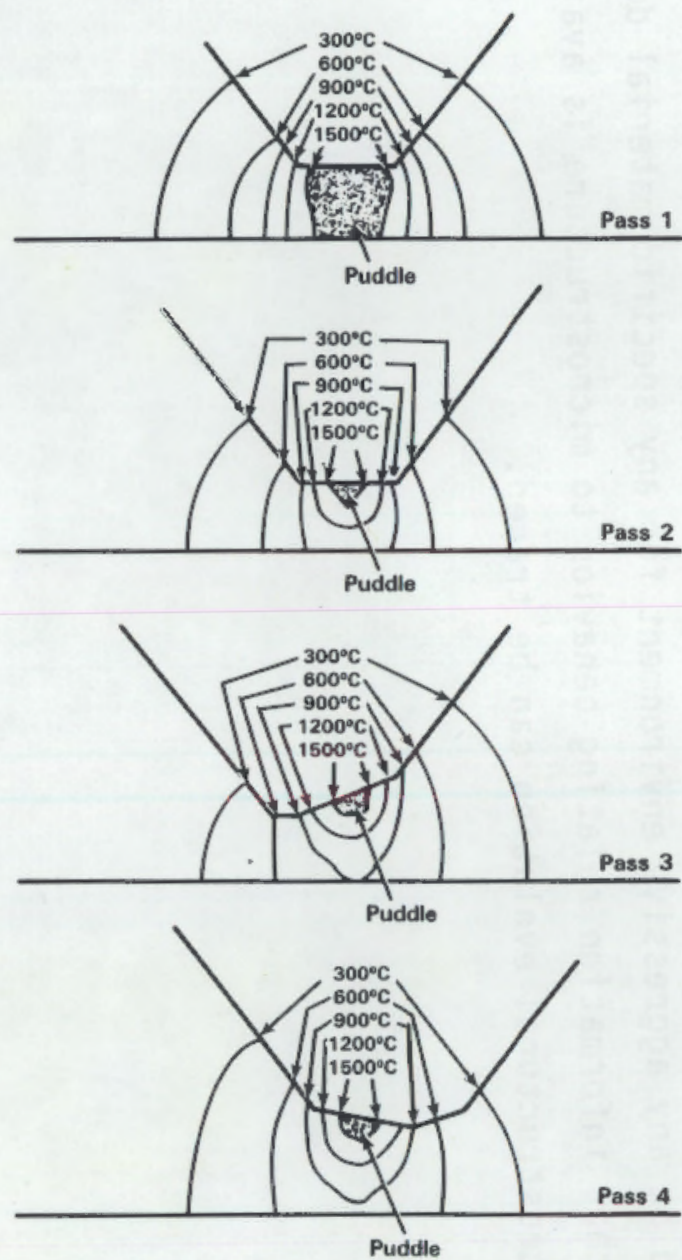

Pass 4

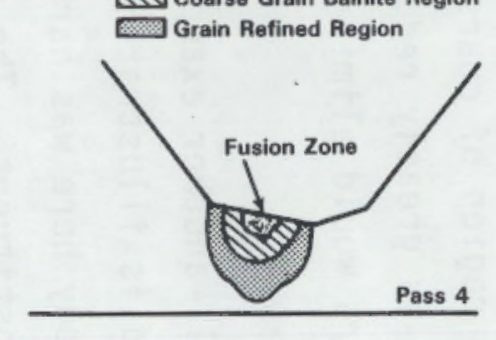

Resultant Coarse Grained Zones
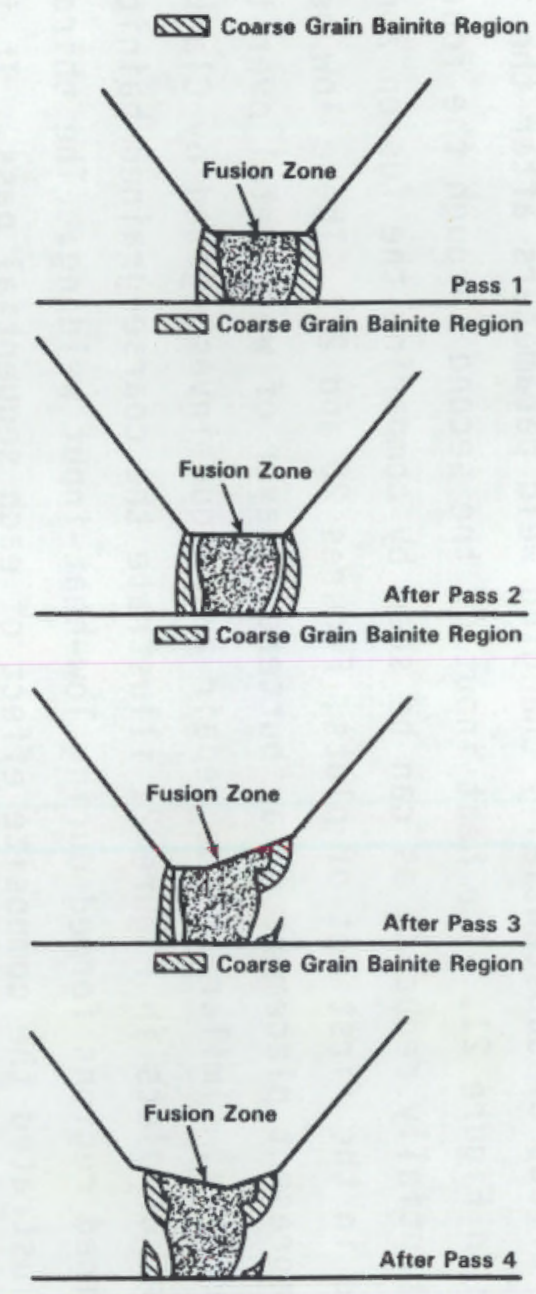

FIGURE 21. Prediction of Coarse-Grained Regions in 24-in.-dia. CS Pipe Girth Weld Fabricated Using Butter-Bead Technique from FEM-Predicted Isotherms 


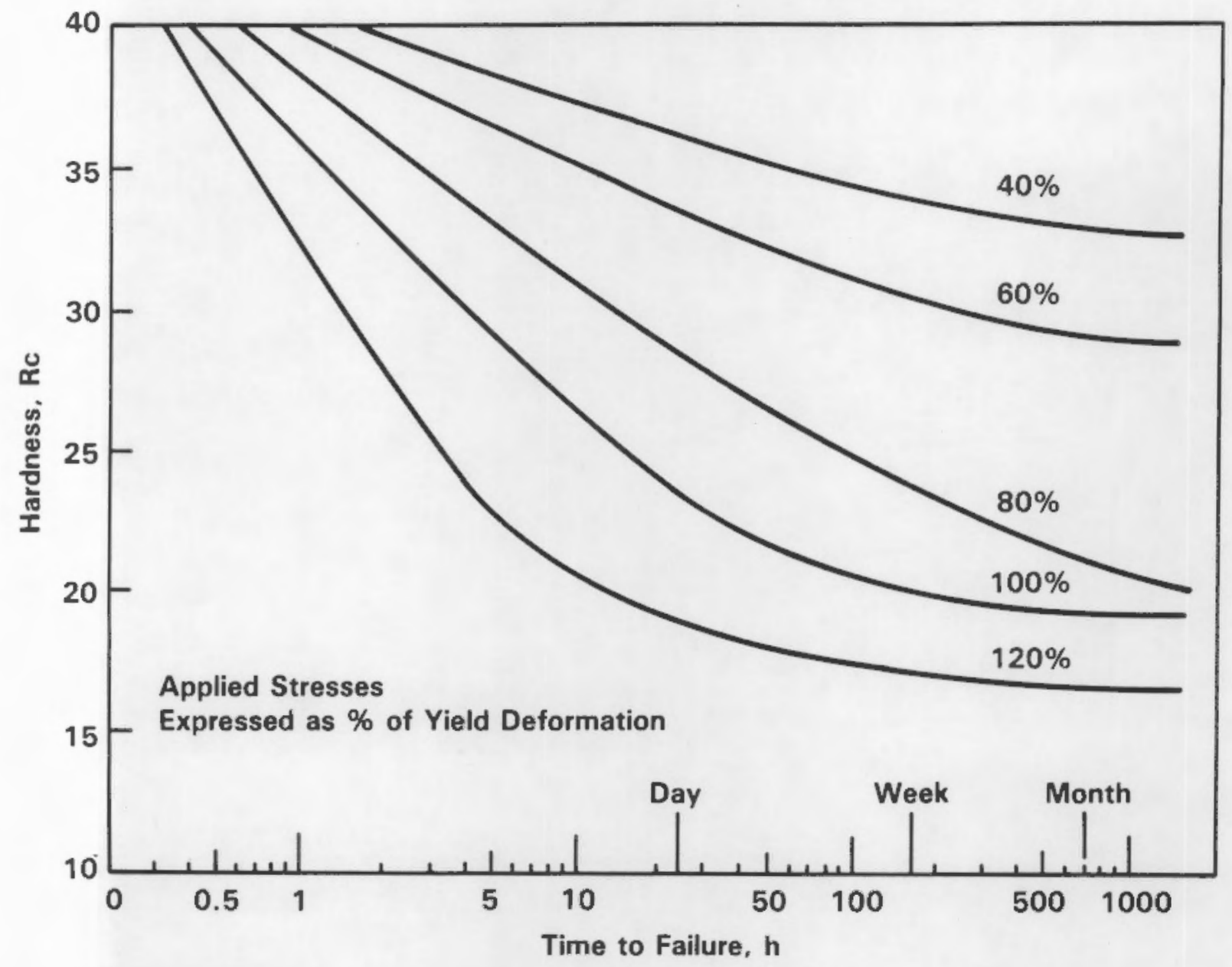

FIGURE 22. Approximate Correlation of Hardness, Time to Failure, and Applied Stress for CS for 3000 ppm Hydrogen Sulfide in a $5 \% \mathrm{NaCl}$ Solution 

It has been determined that it is feasible to develop a computer-based Hanford Site-specific weld modeling capability. Initial near-term modeling efforts would result in realistic modeling of the HAZ within a year of program initiation. Long-term modeling efforts would result in complete weldment and structural component modeling capabilities.

The type of empirically based weld HAZ embrittlement prediction models demonstrated in Task 3 could be readily set up as a follow-on to development of the weld thermomechanical prediction capability being assessed in Task 1 . The weld TM prediction model would be used to predict the required hardness or presence of susceptible microstructure for a specific welding situation. A generic model that could be used for analysis of Hanford Site welds could be prepared using empirical relationships presented in the open literature. Final adjustment of the model to specific Hanford Site weldments would be achieved through an experimental weld matrix that included Hanford Site-specific materials, such as previously proposed to UNC by PNL for developing site-specific welding parameters for the temper-bead weld repair technique.

The development of a Hanford Site weld modeling program with which weld engineering personnel can successfully interact is expected to be a multiyear project. Near- and long-term recommended goals are presented below.

\section{NEAR-TERM MODELING GOALS}

- Modeling thrust will be toward predicting welding parameter envelopes based on acceptabTe HAZ microstructure.

- The majority of the models will be empirically based.

- Initial thermal model predictions will use the commercially available FEM program ANSYS.

- The Goldak model will be used as the basis for development work toward increased FEM accuracy, efficiency, and usability. 
- The FEM analysis work will be performed by personnel trained in finite element computation techniques.

LONG-TERM MODELING GOALS

- Modeling thrust will be toward predicting welding parameter envelopes based on acceptable fusion zone and HAZ microstructures and structural component integrity.

- The model(s) will be based on first principles.

- The Goldak model will be used as the basis for the TM history FEM development work.

- All model predictions will be manipulable by welding engineers. 
1. Key, J. F., M. E. McIlwain and L. Isaacson. 1980. "A Plasma Diagnostics Approach to Welding Heat Source/Molten Pool Interaction." Gas Discharges and Their Applications. Conf. Pub. 189, Part 2, pp. 235-238, September 8 through 11, 1980. Proceedings 6th International Conference, Edinburg, Scotland.

2. Key, J. F., H. B. Smartt, J. W. Chan and M. E. McIlwain. 1982. "Arc Physics and Heat Flow in Gas Tungsten Arc TIG Welding." Welding Technology 82, pp. 279-287, October 9 through 15, 1982. Proceedings 30th Annual American Welding Institute Convention, Hobart, Tasmania.

3. Key, J. F., J. W. Chan and M. E. McIlwain. 1983. "Process Variable Influence on Arc Temperature Distribution." Welding J. 62(7):179s-184s.

4. Key, J. F. 1980. "Anode/Cathode Geometry and Shielding Gas Interrelationships in GTAW TIG Welding." Welding J. 59(12):364s-370s.

5. Heiple, C. R., J. R. Roper, R. T. Stagner and R. J. Aden. 1983. "Surface Active Element Effects on the Shape of GTA TIG, Laser and Electron Beam Welds." Welding J. 62(3):72s-77s.

6. Heiple, C. R. and J. R. Roper. 1982. "Mechanism for Minor Element Effect on GTA TIG Welding Fusion Zone Geometry." Welding J. 61:97s-102s.

7. Goldak, J. A., A. Chakravarti and M. J. Bibby. 1984. "A New Finite Element Model for Welding Heat Sources." AIME 15B:299-305.

8. Kaufmann, E. N., R. J. Wallace, K. W. Mahin, C. J. Er, and F. J. Huegel. 1984. "Biform Resolidification and Amorphous Phases in a Laser and Electron Beam Processed Tantalum-Iridium Alloy." MRS European Meeting, Strasbourg, France, June 5, 1984, UCRL-90624, Conference-8406129-2. Lawrence Livermore National Laboratories, California.

9. Mahin, K. W., A. Shapiro and J. Hallquist. 1986. "Metallurgy and Weld Modeling--Can We Bridge the Gap?" In Intern. Trends in Welding Res., ed. S. A. David. American Society for MetaTs, Metals Park, Ohio.

10. Goldak, J., M. McDill, A. Oddy, M. J. Bibby, R. House, and X. Chi. 1986. "Computational Heat Transfer for Weld Mechanics." Intern. Trends in Welding Res., ed. S. A. David. American Society for Metals, Metais Park, ohio.

11. Goldak, J. A. Oddy, M. McDill, M. J. Bibby and R. House. 1986. "Progress in Computing Residual Stress and Strain in Welds." Intern. Trends in Welding Res., ed. S. A. David. American Society for Metals, Metals Park, ohio. 
12. Goldak, J., A. B. Pate1, M. J. Bibby and J. E. Moore. 1985. "Computational Weld Mechanics." Invited Opening Paper for AGARD Workshop-Structures and Materials 61st Panel Meeting, Oberammergau, Germany, September 8 through 13, 1985.

13. Atterjdge, D. G., and S. M. Bruemmer. 1986. "Evaluation of Welded and Repair-Welded Stainless Steel for LWR Service." Annual Report for October 1984 Through September 1985. NUREG/CR-3613 (PNL-4941), Vol. 3, No. 2, prepared for Nuclear Regulatory Commission by Pacific Northwest Laboratory, Richland, Washington.

14. Bruemmer, S. M. and L. A. Charlot. 1986. "Measurement and Prediction of Thermomechanical History Effects on Sensitization Development in Austenitic Stainless Steels." Paper No. 242 in CORROSION "86, National Association of Corrosion Engineers, Houston, Texas.

15. Charlot, L. A., B. W. Arey and S. M. Bruemmer. 1986. "Strain Effects on Sensitization Development in 304 Stainiess Steel as Measured by EPR and STEM/EDS Methods." In Proceedings for Symposium on Materials Characterization, Materials Research Society, Pittsburgh, Pennsylvania.

16. Mehrotra, V., M. Bibby, J. Goldak and J. Moore. 1984. "A Microcomputer Method for Predicting Preheat Temperatures." Department of Mechanical and Aeronautical Engineering, Carleton University, Ottawa, Canada.

17. Shing, G. M., J. Bibby and J. A. Goldak. 1985. "A Microprocessor Model for Predicting HAZ Hardness." SAMPE Quarterly.

18. Clark, J. N. 1986. "Manual Metal Arc Weld Modeling: Part 1 - Effect of Process Parameters on Dimensions of Held Bead." Materials Science and Technology $1(12)$.

19. Clark, J. N. 1986. "Manual Metal Arc Weld Modeling: Part 2 - Treatment of Multipass Weld." Materials Science and Technology 1(12).

20. Clark, J. N. 1986. "Manual Metal Arc Weld Modeling: Part 3 - Implementation of Two-Layer Heat-Affected Zone Refinement Technique Under Shop Floor Conditions." Materials Science and Technology 1(12).

21. Clark, J. N., and J. A. Lambert. 1986. "Controlled, All-Position, Butter-Bead-Temperbead Welding Technique for Nuclear Repairs." Welding Journal 65(2).

22. Stout, R. D. 1973. "Hardness as an Index of the Weldability and Service Performance of Steel Heldments." WRC Bu11. 189, November 1973. 


\section{$\underline{\text { DISTRIBUTION }}$}

No. of

Copies

OFFSITE

30 DOE Technical Information

Center

ONSITE

DOE Richland Operations Office

D. R. Segna

2 Rockwell Hanford Operations

J. R. Hauptmann (2)

2 UNC Nuclear Industries, Inc.

J. J. Sisk (2)

24 Pacific Northwest Laboratory

W. E. Anderson

D. G. Atteridge (3)

R. F. Klein (10)

R. E. Page

J. P. Pilger

P. L. Whiting

Publishing Coordination (2)

Technical Information (5) 


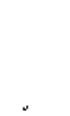

